INTERNATIONAL

FOOD POLICY

RESEARCH

INSTITUTE

IFPRI

IFPRI Discussion Paper 01508

February 2016

\title{
Is Access to Tractor Service a Binding Constraint for Nepali Terai Farmers?
}

Hiroyuki Takeshima

Rajendra Prasad Adhikari

Anjani Kumar

Development Strategy and Governance Division 


\section{INTERNATIONAL FOOD POLICY RESEARCH INSTITUTE}

The International Food Policy Research Institute (IFPRI), established in 1975, provides evidence-based policy solutions to sustainably end hunger and malnutrition and reduce poverty. The Institute conducts research, communicates results, optimizes partnerships, and builds capacity to ensure sustainable food production, promote healthy food systems, improve markets and trade, transform agriculture, build resilience, and strengthen institutions and governance. Gender is considered in all of the Institute's work. IFPRI collaborates with partners around the world, including development implementers, public institutions, the private sector, and farmers' organizations, to ensure that local, national, regional, and global food policies are based on evidence. IFPRI is a member of the CGIAR Consortium.

\section{AUTHORS}

Hiroyuki Takeshima (h.takeshima@cgiar.org) is a research fellow in the Development Strategy and Governance Division of the International Food Policy Research Institute (IFPRI), Washington, DC.

Rajendra Prasad Adhikari is joint secretary of the Policy and International Cooperation and Coordination Division of the Nepal Ministry of Agriculture Development, Kathmandu, and a research fellow in Value Chain Management, University of Tasmania, Hobart, Australia.

Anjani Kumar is a research fellow in the South Asia Office of IFPRI, New Delhi.

\footnotetext{
Notices

1. IFPRI Discussion Papers contain preliminary material and research results and are circulated in order to stimulate discussion and critical comment. They have not been subject to a formal external review via IFPRI's Publications Review Committee. Any opinions stated herein are those of the author(s) and are not necessarily representative of or endorsed by the International Food Policy Research Institute.

2. The boundaries and names shown and the designations used on the map(s) herein do not imply official endorsement or acceptance by the International Food Policy Research Institute (IFPRI) or its partners and contributors.

Copyright 2016 International Food Policy Research Institute. All rights reserved. Sections of this material may be reproduced for personal and not-for-profit use without the express written permission of but with acknowledgment to IFPRI. To reproduce the material contained herein for profit or commercial use requires express written permission. To obtain permission, contact ifpri-copyright@cgiar.org.
} 


\section{Contents}

Abstract $\quad$ V

Acknowledgments $\quad$ vi

1. Background 1

2. Tractor Adoption Level and Tractor Size: Historical and International Perspectives 2

2. Conceptual Framework $\quad 4$

3. Empirical Analysis $\quad 6$

5. Empirical Results 15

6. Conclusions and Key Policy Implications 23

$\begin{array}{ll}\text { References } & 24\end{array}$ 


\section{Tables}

4.1 Key Nepali agricultural research stations used in the model 11

4.2 Descriptive statistics of variables used (raw data combining three rounds of the NLSS)

5.1 Determinants of tractor use based on Heckman's (1979) maximum likelihood estimation model, extended to include pseudo-panel-correlated random effects

5.2 Estimated wedges due to imperfections in the tractor hiring market in the Terai region of Nepal (\% differences in per capita real expenditures)

5.3 Balancing sample properties using propensity score matching

5.4 Conditional expectations of outcomes estimated using generalized propensity scores (cross-section data) in the Terai region of Nepal

\section{Figures}

2.1 Average tractor horsepower and level of mechanization (various years) 2

4.1 Distinction between the impacts of marginal adoption and intensive technology adoption 7

5.1 Distribution of estimated propensity scores by tractor use status among households not owning tractors in the Terai region of Nepal

5.2 Heterogeneous effects of tractor adoption on earned income and cumulative distribution of propensity scores to rent in tractors in the Terai region of Nepal, 2010

5.3 Insignificant income effects of tractor rental intensity for annual tractor rental expenses equivalent to $\leq 250 \mathrm{~kg}$ of cereals 


\begin{abstract}
Using results from the three rounds of Nepal Living Standard Surveys (conducted in 1995, 2003, and 2010), this study empirically assesses whether access to rented tractors or custom hiring services is a binding constraint on the income growth of farm households in Nepal. Because four-wheel tractors of medium horsepower are still the primary suppliers of these tractor services, access to these services can be restricted. First, we investigated the determinants of the adoption of hired tractors as well as the intensity of their use (measured by real annual expenditures on renting tractors). Results suggest that the adoption and the intensity patterns are generally consistent with the conventional theory of the demand for agricultural mechanization, indicating that the supply of these services may be relatively efficient in meeting the demand. However, adoption is still affected by the presence of tractor owners within the same village district committee, indicating that the proximity to tractor service providers may still partly determine accessibility. This second point was more formally tested using matching estimators within the Terai region of Nepal. It was found that, on average, the supply of tractor services might have evolved to a relatively efficient level in the Terai so that those who benefited from renting in tractors generally had access to such services. However, for at least certain segments of farm households in the Terai, insufficient access to tractor services was still a binding constraint on the growth of farm household incomes. The policy implications of these findings are briefly discussed in the last section.
\end{abstract}

\title{
Keywords: tractor rental, access constraint, propensity score matching, heterogeneous treatment effect, generalized propensity score matching, Nepal
}




\section{ACKNOWLEDGMENTS}

We would like to thank the United States Agency for International Development (USAID) for providing funding for this study through its Policy Reform Initiative Project (PRIP). We are also grateful for the constructive comments received from the participants of a stakeholder consultation meeting held on September 2, 2015, in Kathmandu, Nepal. We also thank Madhab Karkee and Deva Bhakta Shakya for their overall guidance and facilitation of this work. We are responsible for all remaining errors. 


\section{BACKGROUND}

The use of tractors has grown steadily in Nepal, particularly in the Terai region (Takeshima et al. 2015a). The majority of reported tractor use is based on custom hiring by tractor owners, an increasingly important pattern of mechanization outsourcing by farmers in developing countries, also observed in China (Zhang et al. 2015) and in African countries such as Ghana (Diao et al. 2014) and Nigeria (Takeshima et al. 2015b). While the number of small two-wheel tractors is growing in Nepal, four-wheel (typically 30 horsepower) tractors are still believed to be widely used for custom hiring by private tractor owners, particularly in the Terai. This relative dominance of four-wheel tractors is a pattern similar to that of other South Asian countries, such as India, but differs from that of many other Asian countries where a majority of tractors are two-wheel and have much lower horsepower.

While custom hiring of large four-wheel tractors can exploit economies of scale, market imperfections remain because of the inherent indivisibility of this technology, among other factors. For example, a recent study in Nigeria indicated substantial imperfections in the tractor hiring service market (Takeshima 2015b). The limited mobility of tractors does not substantially constrain access to hiring them if tractor density is sufficiently high so that mobility is required only within a small geographical area. However, as reported by Takeshima, Adhikari, and Poudel (2015a), tractor density is still low in Nepal compared with some other Asian countries, and there may be substantial areas where lack of access to tractors for hiring is a binding constraint on farm households.

This study assesses issues related to the tractor hiring service market in Nepal. Adding to the results from the study in Nigeria (Takeshima 2015b), Nepali data allow us to obtain further insights into how evidence consistent with market imperfection is heterogeneous among farm households. That is, in some districts, no evidence shows that access to tractors is constraining farm households' economic behaviors, consistent with the view that the supply of mechanization services emerges efficiently in response to demand, whereas in districts in which the level of tractor hiring is low, hiring tractors leads to a substantial increase in household income, consistent with the hypothesis that access to tractor hiring services can be severely limited despite potentially high demand (see Binswanger 1986). This observation is consistent with the limited spatial mobility of tractor hiring services, combined with demand seasonality (seen in other developing countries) that similarly relies on (high-horsepower) four-wheel tractors for hiring services (Takeshima et al. 2015b). 


\section{TRACTOR ADOPTION LEVEL AND TRACTOR SIZE: HISTORICAL AND INTERNATIONAL PERSPECTIVES}

Some unique characteristics of tractors differ from those of other inputs: their bulkiness and often scalebiased nature. These characteristics are often more pronounced for higher-horsepower tractors. Therefore, prevailing types of tractors (such as average horsepower) in a country have important implications for how the market structures of tractor supply and its related services affect accessibility to this type of equipment. Specifically, accessibility may be limited or highly skewed in societies where the proportion of land plowed by tractors is low (indicating that tractors are few and sparsely distributed) and the average horsepower of the tractors is high (that is, the area is plowed by fewer tractors).

Figure 2.1 illustrates the historical relationship between the share (\%) of land area plowed by tractors and the average horsepower of tractors in various countries. Although this information is somewhat limited and provides only a few data points, it does provide insights into the diverse patterns seen across regions. For example, in China between 1978 and 2010, the average tractor horsepower declined as the area plowed by tractors grew. This pattern was the opposite of that seen in the United States.

Figure 2.1 Average tractor horsepower and level of mechanization (various years)

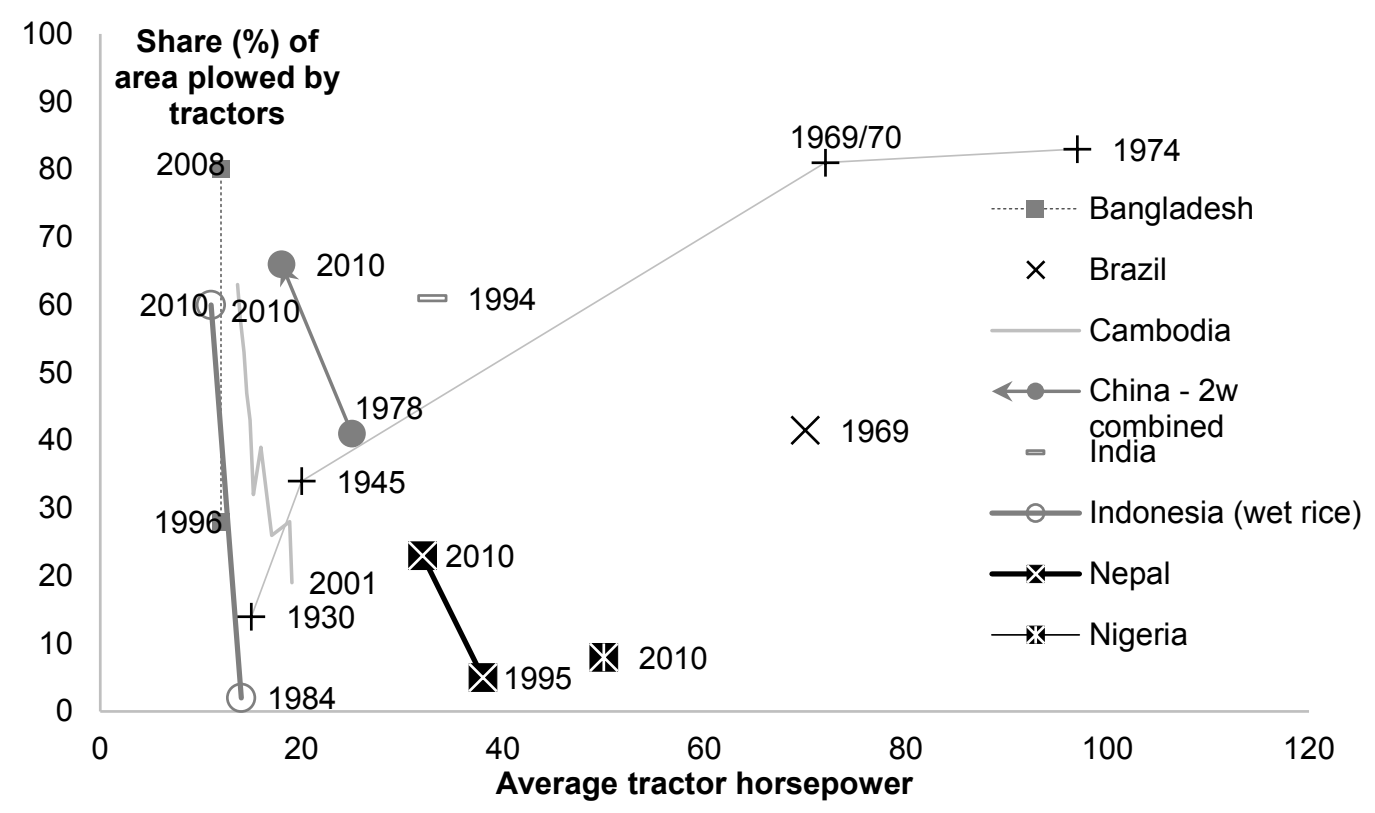

Source: Author's calculations based on CSAM (2014) for China; Kienzle et al. (2013) and Roy and Singh (2008) for Bangladesh; Stitzlein (1974) for Brazil; Ugwuishiwu and Onluwal (2009, Table 2.1) for India; Olmstead and Rhode (2001) and Gardner and Pope (1978) for the United States; Thorbecke and van der Pluijm (1993, 111) and CSAM (2014) for Indonesia; and Takeshima and Salau (2010), Takeshima et al. (2015b), and informal communications with local experts for Nigeria.

Notes: The data for the United States represent the share of farmers using tractors. The data point for Brazil is for wheat only and represents the average of the Rio Grande du Soil and Santa Katarina areas reported by Stitzlein (1974, Table 7).

Average horsepower for the United States is reported in Gardner and Pope (1978, p. 298) for 1970 and 1975. The average horsepower for tractors was calculated assuming that horsepower for fourwheel tractors and two-wheel tractors are 42 and 11, respectively, adopting the definitions used in China. Numbers within the figure correspond to years. 
Since 1995, Nepal appears to have been following the past Chinese pattern. However, it is unclear whether the growth pattern is fast enough - particularly in the Hills and Mountains. The speed of adoption in Nepal has also been relatively slow compared with that of other Asian countries, such as Bangladesh, Cambodia, and Indonesia. In addition, the recent growth of tractor use in the Terai has still been led by the use of relatively large tractors, in which one tractor owner typically serves more than 20 farm households (Takeshima et al. 2015b). These patterns suggest that tractor accessibility still may be a binding constraint on many farmers in Nepal. This finding motivated our study investigating the indirect evidence of accessibility constraints. 


\section{CONCEPTUAL FRAMEWORK}

We were interested in testing whether the lack of (or insufficient) access to custom-hired tractors is a binding constraint on farm households in Nepal in terms of increasing their incomes. Our empirical approach was to test the indirect evidence for this hypothesis by examining the impact of marginal tractor adoption on household incomes. A similar analysis had been conducted for Nigeria based on the same premises, conceptual framework, and empirical approach (Takeshima 2015b). Below, we summarize the conceptual framework and problem statements described in Takeshima (2015b).

\section{A Simple Conceptual Illustration}

A standard profit maximization theorem suggests that, if there is no market imperfection in the supply and demand for custom hiring services, the marginal adoption of such services should have no effect on household profits because the marginal revenue equals the marginal costs of adoption. If a marginal adoption does have a significant impact (separate from the intensity effect), then the impact is likely the result of the (treatment group) household overcoming the market imperfection, while other similar (control group) households did not. Below we illustrate a household's decision mechanism for adopting technology whose supply market is imperfect. This scenario can be described in one way by a mixedregime model in which a household faces fixed transaction costs in switching from a no-adoption state to an adoption state (Takeshima and Winter-Nelson 2012; Takeshima and Nkonya 2014). A household's profit maximization formula follows:

$$
\max _{I_{r}, L_{r}, M_{r}} \Pi=I_{0} \cdot\left[F_{0}\left(L_{0} ; z\right)-p_{L} L_{0}\right]+I_{1} \cdot\left[F_{1}\left(L_{1}, M_{1} ; z\right)-p_{L} L_{0}-p_{M} M_{1}-\eta\right]
$$

subject to

$$
\begin{aligned}
& I_{0}+I_{1}=1 \\
& L_{r}, M_{r} \geq 0 \quad \forall r,
\end{aligned}
$$

where the profit $\Pi$ depends on the output $F_{r}$, labor costs (= labor use $L_{r} \times$ unit price $p_{L}$ ), and the cost of mechanization services (intensity $M_{1} \times$ unit price $p_{M}$ ). For simplicity, we assumed that labor and machinery are the only inputs. The farmer faces two possible regimes $r: r=0$ is a "constrained" regime in which no tractor service is available, whereas $r=1$ is an "unconstrained" regime in which tractor service is available. The household starts from regime $0\left(I_{0}=1\right)$ and decides whether to move to regime 1 . If the tractor hiring market is imperfect, positive transaction costs $\eta$ are associated with switching to regime 1 owing to the various constraints, including the limited mobility of tractors discussed in earlier sections.

If the tractor hiring market is perfect, and $\eta=0$, decisions pertaining to $I$ are irrelevant and the model reduces to

$$
\max _{I_{r}, C_{r}, X_{r}} \Pi=F(L, M ; z)-p_{L} L-p_{M} M
$$

since $\partial F / \partial M=p_{M}, \partial F / \partial L=p_{L}$, and

$$
\left.\frac{\partial \Pi}{\partial M}\right|_{\frac{\partial F}{\partial M}=p_{M}}=\frac{\partial F}{\partial M}-p_{M}=0
$$

and a marginal increase of $M$ from $M=0$ has no effect on $\Pi$. 
When the tractor hiring market is imperfect, $\eta>0$. In this case, a marginal increase in $\mathrm{M}$ increases $\Pi$ by the following formula:

$$
-\int_{L^{*}}^{L_{0}}\left(\frac{\partial F\left(L, M_{0}\right)}{\partial L}-p_{L}\right) d L+\int_{M_{0}}^{M^{*}}\left(\frac{\partial F\left(L^{*}, M\right)}{\partial M}-p_{M}\right) d M,
$$

where $L^{*}$ and $M^{*}$ are global optimal solutions under both regimes. (3) calculates a "wedge" arising from inefficient resource allocation owing to the imperfection of the tractor hiring market. Based on the linear integral theory, the first term represents the loss resulting from using less labor (as a result of substitution with the use of $M$ ) measured at the initial condition $M=M_{0}=0$. However, the whole term is nonnegative because the second term, which represents the benefits from tractor use, is positive and offsets the loss in the first term. The wedge (3) becomes positive along with a marginal increase in $M$ from $M=0$. In other words, marginal tractor adoption increases profit if $\eta>0$ owing to the failure in the tractor hiring market. Arguably, a positive $\eta$ likely results from the imperfection in the tractor hiring market rather than any other causes. For example, tractor hiring service suppliers may also address other market imperfections by providing information on improved production practices or offering goods (such as fertilizer) and services (credit and insurance) that would be otherwise unavailable to farmers. If hiring service suppliers were the sole suppliers of such information, goods, and services, then inaccessibility to such hiring services could lead to positive $\eta$ and to wedge (3), even if the hiring service market were perfect. However, given the heterogeneity of production environments, information on production practices is less transferrable across farmers, particularly for rice (Munshi 2004), which is often one of the most tractorized crops in Nepal. Given their low mobility, tractors may be less effective than motorcycles or trucks for transporting goods to remote areas where their supplies are limited. Thus, suppliers of hiring services are less likely to address market imperfections in other goods for farmers. Similarly, although suppliers of hiring services may provide services on credit, which could partly address credit market failures for farmers, similar arrangements may exist to varying degrees for other inputs such as fertilizer or hired labor, which are more widely adopted in Nepal (Takeshima et al. 2015b). Therefore, access to tractor hiring services is unlikely to be the sole source of credit to farmers and therefore unlikely to reduce $\eta$, which is associated with credit market imperfection. These conditions suggest that a positive $\eta$ is more likely to result from market imperfections in tractor hiring supply. 


\section{EMPIRICAL ANALYSIS}

Our empirical analyses focused on obtaining insights into the accessibility of tractor hiring services highlighted in the previous sections. Specifically, we first assessed the determinants of rented tractor use and use intensity, measured as real expenditures on tractor rentals, and examined the extent to which they were affected by demand. We then sought evidence consistent with the hypothesis of constrained access to custom hiring of tractors.

\section{Determinants of Rented Tractor Use and Use Intensity}

\section{Model Specifications}

The empirical analysis used transaction costs literature that tested the presence of hurdles by identifying differentiated mechanisms that affect entry into a certain regime and the economic behaviors that take place within such regimes (see, for example, Key et al. 2000; Bellemare and Barrett 2006; Takeshima, Adeoti, and Salau 2011; Takeshima and Winter-Nelson 2012;). These studies, however, did not quantify the economic significance of these hurdles and thus provide only limited insights into the importance of market failure.

\section{Heckman's Model (1979) Using Pseudo-Panel-Correlated Random Effects}

Taking advantage of the three rounds of Nepal Living Standard Surveys (NLSS), conducted in 1995, 2003, and 2010, pseudo-panel data were constructed with districts serving as cohorts. Since the use of tractors for many households is zero (corner solution), we employed the correlated random effects (CRE) model (Chamberlain 1984), which approximates unobserved fixed effects in a model like Heckman's (1979). We extended the CRE model to analyze pseudo-panel data, in which the average values across three rounds of NLSS for various exogenous covariates from all samples in each district were used to approximate various unobserved fixed effects of the households.

Farm households' decisions as to whether and how much to use tractors can be modeled as follows:

$$
\begin{array}{ll}
d^{0}=f(Z, X) & \\
d^{1}=f(Z, X) & \text { if } d^{0}=1 \\
\ln (T)=f(X) & \text { if } d^{1}=1
\end{array}
$$

where $d^{0}=1$ if the farm household has access to a custom hiring market ( $d^{0}=0$ otherwise), $d^{l}=1$ if the farm household actually hires tractor services $\left(d^{0}=0\right.$ otherwise $)$, and $\ln (T)$ is the natural log of hiring in intensity measured as the real annual expenditures on a rented tractor $(T) . Z$ comprises a set of factors affecting the access of a farm household to the tractor hiring service market, while $X$ is a set of factors that affects all of $d^{0}, d^{l}$, and $T$.

In our data, only $d^{l}$ (which is nested within $d^{0}$ ) was observed, whereas $d^{0}$ was not observed. Assuming that factors affect $d^{0}$ and $d^{l}$ in the same way (that is, with the same signs and statistical significance), the two stages $d^{0}$ and $d^{l}$ can be approximated by a reduced-form probit in which the dependent variable $d^{*}=d^{0} \cdot d^{l}$ is regressed on $Z$ and $X$. In this way, a statistically significant coefficient for $Z$ in the reduced-form probit is a weak indication of its statistically significant effect on $d^{0}$. The third stage can be estimated using an ordinary regression model, making (4) equivalent to Heckman's (1979) sample selection model. If factors affect $d^{0}$ and $d^{l}$ differently, partial observability probit can be used to partly overcome the unobservability of $d^{0}$ (Poirier 1980; Abowd and Farber 1982). The results may be, however, susceptible to the specifications of each stage. We therefore used reduced-form probit.

Key variables expected to affect the demands for tractors were identified from the agricultural mechanization literature. 


\section{Income Effects of Rented Tractor Use at Extensive and Intensive Margins: Matching Estimators}

The conceptual framework set forth in Section 3 above suggests that, if marginal adoption of a tractor significantly increases a household's overall profits, it can also indicate the failure of the tractor hiring market. However, for scale-biased technologies like tractors, treating the adoptions as binary (as in conventional technology adoption studies) cannot distinguish the effects of marginal adoption from those of intensive adoption (Figure 4.1). If the increase in $M$ from $M=0$ is large (that is, intensive adoption of tractors), the term (3) can be positive even if the market is perfect and $\eta=0$. This occurs because the first-order condition (2), which is based on a marginal change in $M$, breaks down if an increase in $M$ is large enough.

Figure 4.1 Distinction between the impacts of marginal adoption and intensive technology adoption
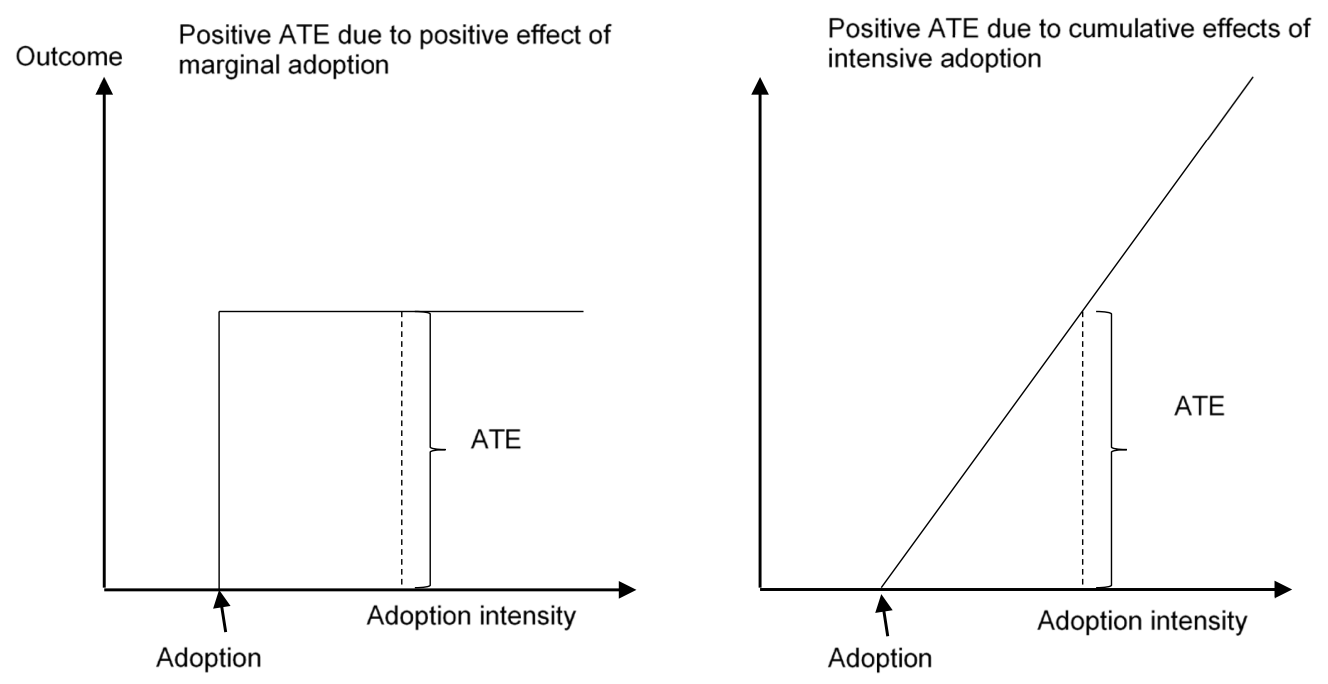

Source: Author.

Note: $\quad$ ATE $=$ Average treatment effect.

One possible specification is to include both the binary variable (indicating the adoption) and the continuous variable (measuring adoption intensity) and to separate out the effects of intensive adoption from those of marginal adoption. However, in many cases, both marginal and intensive technology adoptions are potentially endogenous to the outcome variables. Instrumental variable methods, such as two-stage least squares (2SLS), are challenging because the continuous endogenous variable depends on the binary endogenous variable. The literature is sparse regarding how such mechanisms can be appropriately modeled using 2 SLS. In addition, finding robust instruments for both marginal and intensive adoption variables is likely to be difficult.

In addition, 2SLS may be sensitive to the violation of the linearity assumption. Imbens and Rubin (2009) suggested that if normalized differences of covariates between treatment and control groups are greater than 0.25 , then assessing the treatment effects based on linear regression is likely to be susceptible to specification, and alternative models (for example, matching methods) are more suitable. In our study, the normalized differences often exceeded 0.25 for quite a few covariates.

We addressed this issue in the following way: first, we used matching estimators such as the propensity score matching (PSM) method (Rosenbaum and Rubin 1983) as well as the Mahalanobis covariate matching to test whether marginal adoption of tractor use has had significant effects on a key outcome variable in the Terai zone of Nepal. PSM has been increasingly used in the literature for evaluating the effects of agents' behaviors within a nonintervention context, such as technology adoption (Mutuc et al. 2013) or market participation (Takeshima and Nagarajan 2012). We employed PSM by 
excluding intensive users of tractors from the sample and checking the sensitivity of the results for potential bias due to the exclusion of intensive adopters. Matching estimators were obtained for both the cross-section sample and the panel sample in the NLSS. For the panel sample, difference-in-difference (DID) matching estimators (Heckman, Ichimura, and Todd 1997, 1998; Smith and Todd 2005) were obtained, which can further reduce biases due to unobserved household fixed time-invariant effects (albeit at the loss of some efficiency owing to smaller panel sample sizes than cross-section sample sizes in the NLSS).

For the PSM, we assessed the heterogeneity of such effects using the approach developed by Xie, Brand, and Jann (2012). This approach accounts for the effects of marginal adoption of tractors possibly varying based on farm household characteristics - in particular, the propensity to adopt rented tractors.

We then used generalized PSM (GPSM) methods (Hirano and Imbens 2004) to confirm that the effects of adoption intensity were insignificant among these marginal adopters and that the significant effects from matching estimators were the result of marginal adoption of tractors rather than adoption intensity. Detailed descriptions of GPSM methods are provided in Hirano and Imbens (2004) and Takeshima (2015a), which analyzed similar issues in Nigeria. GPSM essentially involves estimating generalized propensity score (GPS) based on the estimated conditional density of treatment intensity, and uses the GPS in a similar way as PSM uses the ordinary propensity score. Dose-response function estimated with GPSM can inform whether treatment effects vary according to treatment intensity, upon receiving the treatment.

\section{Matching Estimators}

The effects of marginal adoption of rented tractors were estimated through a series of matching estimators, including the average treatment effects on the treated (ATTs) and heterogeneous treatment effects on the treated (HTTs).

PSM was estimated using psmatch2 (Leuven and Sianesi 2003) and teffects psmatch commands in Stata software (STATACorp LP). We used both commands for various reasons. First, teffects psmatch is likely to provide more consistent estimates of the standard errors of the estimated effects, which are based on Abadie and Imbens (2012), whereas psmatch2 does not take into account the fact that propensity scores are estimated (Leuven and Sianesi 2003). On the other hand, several built-in commands in Stata, such as rbounds (DiPrete and Gangl 2004) for estimation of Rosenbaum bounds (Rosenbaum 2002), are compatible with psmatch2 only.

When estimating propensity score, we dropped the district time-average variables to minimize the effects of the "curse of dimensionality." We also did so because overspecifying the propensity scores may have actually biased the results (Zhao 2008).

One of the matching methods in PSM sets the maximum allowable distance of propensity scores between matched observations (caliper). One shortcoming of the caliper method is that the literature has not clarified how the propensity score should be estimated in the presence of observations that have no suitable match within the caliper. Specifically, authors have not agreed on whether the propensity score must be re-estimated excluding those observations or whether the propensity score from the original sample can be used. Software commands like teffects psmatch in Stata make it mandatory that new propensity scores be estimated, whereas psmatch 2 simply drops those observations and uses the original propensity scores to proceed with the matching. Owing to this lack of clarity, we estimated propensity scores in an iterative manner: after each run of propensity score estimation, observations without a suitable match within the caliper were excluded and new propensity scores were estimated. We repeated this procedure until we ended up with only observations that had suitable matches within the caliper.

The consistency of PSM depends on unconfoundedness assumptions, which can fail if unobserved characteristics differ significantly across agents. If panel data are available, this problem can be mitigated by combining DID methods with PSM (DID-PSM) (Heckman Ichimura, and Todd, 1997, 1998; Smith and Todd 2005), which can net out such unobserved fixed effects. The NLSS includes a 
small section of the sample consisting of a panel. We applied DID-PSM to this sample to see whether the findings from the cross-section data were robust. For 2003 and 2010 panel households, we computed $y_{i t}-$ $y_{i, t-1}$, which is the growth rate of real per capita income (the income variable is defined in the section “Overall Household Profit $\Pi$ ”). By notating tractor adoption status as $t-1$ and $t$ as yes/no, four types of households emerged for both 2003 and 2010 data: (a) (no - no); (b) (no - yes); (c) (yes - yes); and (d) (yes - no). Following the descriptions in Heckman, Ichimura, and Todd $(1997,1998)$ and Smith and Todd (2005), (b) became the treatment group while (a) was the control group. Examples of (d), which accounted for only a small share in the sample, were dropped from our study, as this type was not clearly defined in Heckman, Ichimura, and Todd $(1997,1998)$ nor in Smith and Todd (2005).

We also treated (c) as the control group. We did so because although households were in the treatment group in the sense that they used tractors in both periods, they were also in the control group based on the relevant classification here, in which the treatment group consists only of households who newly adopted tractors. The sample (c) was also relatively small. Including them, however, helped us maintain an adequate sample size and more accurately detect the effect of access constraint; this effect should have appeared only for (b) and not for (c), which could be tested only by including (c) in the sample as a control group.

Based on these definitions, each panel sample belonged to either the treatment or the control group. Some panel samples that appeared in all three rounds of the NLSS switched status from the 2003 data to the 2010 data. For example, a household whose tractor adoption status in 1995, 2003, and 2010 was (no - no - yes) was treated as a control group in 2003 data but as a treatment group in 2010. On the other hand, a household whose tractor adoption status was (no - yes - yes) was considered as a treatment group in 2003 but as a control group in $2010 .^{1}$

\section{Data and Descriptive Statistics}

As mentioned earlier, we used data from three rounds of the NLSS, conducted in 1995, 2003, and 2010, respectively. The NLSS contains detailed information on various aspects of household characteristics, including the expenses of rented tractors. To control for heterogeneity in agricultural production environments, we combined NLSS data with various spatial data describing agroecological conditions. The NLSS data were collected by Nepal's Central Bureau of Statistics. In each round of the survey, data were collected based on multistage, stratified random sampling methods. The sampling involved enumeration areas (EAs) that were randomly selected from six strata across Nepal. These EAs consisted of urban and rural areas in each of three agroecological zones: Terai, Hills, and Mountains. ${ }^{2}$ The EAs for NLSS 1995 consisted of 275 wards, from which 3,388 households were sampled. The EAs for NLSS 2003 consisted of 800 EAs, from which 4,008 cross-section samples were randomly selected. In addition, 1,232 panel samples were randomly selected from NLSS 1995. The EAs for NLSS 2010 consisted of 500 EAs redefined from 800 EAs in NLSS 2003, from which 5,988 cross-section samples were randomly selected. In addition, 1,032 panel samples were randomly selected from NLSS 2003 (Nepal CBS 1996, 2004, 2011a).

\footnotetext{
${ }^{1}$ Because the panel sample was considerably smaller than the cross-section sample, we made the following modifications. First, we used caliper 0.1 instead of 0.01 in order to achieve efficient estimates. Second, we included VDCs in which all samples used tractors (there were no nonusers in the sample), whereas such districts were excluded from cross-section analysis above in order to retain better balancing properties. Third, we dropped various independent variables that were highly insignificant to minimize the curse of dimensionality. These included fertilizer price, terrain ruggedness (land that exhibits strong multicollinearity with elevation), size of upland farm owned, and a dummy variable indicating whether the household's main source of water was from the tap (found in very few members of the panel sample).

${ }^{2}$ For NLSS 1995, only the Hills region was further stratified into urban and rural.
} 
Key determinants of the use of rented tractors and use intensity largely consisted of (1) agroecological conditions and (2) socioeconomic conditions. Agroecological conditions included

- soil types,

- rainfall (historical average and standard deviation),

- solar radiation,

- terrain ruggedness,

- elevation, and

- agricultural area per capita in the VDC.

Socioeconomic conditions included

- household size;

- gender and literacy level of the head of household;

- average education level of working-age household members;

- costs of inputs such as chemical fertilizer (urea and diammonium phosphate [DAP], two major types used in Nepal), labor (real wages), and tractor services (tractor rental cost per hour);

- an indicator of irrigation access (sample share of farm households using irrigation within the VDC);

- credit access (indicated by the credit taken in the previous years);

- size of farmland owned (lowland and upland, respectively);

- number of owned plots;

- asset holdings (such as, farmland, livestock, farm equipment);

- whether or not the household owned draft animals;

- access to various facilities and infrastructure;

- factors affecting shadow wages of family members; and

- ethnic background.

Earlier studies suggested that the shadow wages of family labor also affect the demand for labor (Jacoby 1993), and thus, demand for complementary inputs like fertilizer. Jacoby (1993) pointed out that shadow wages of family labor (particularly of female family members) can be affected particularly by whether piped-in water is the main source of drinking water for the household, whether the household owns their house, whether electricity is the main source of light, and whether wood is the main source of cooking fuel. We therefore included dummy variables indicating these.

Indicators of varietal technology levels included technological distance indicators, such as how similar soil and rainfall-risk conditions are to areas where agricultural research stations (ARS) are located. We used the similarity between certain climatic conditions and soil types in the analyses to control for technological distances, which are considered important for determining varietal technology levels (Evenson and Westphal 1995), and potentially, the response of crops to fertilizer.

An important potential determinant of accessibility of tractor service is the presence of tractor owners in the vicinity. Although direct evidence from Nepal is scarce, studies of other developing countries where a majority of farmers rely on custom hiring from the owners of relatively highhorsepower four-wheel tractors have been published. They report that access to tractors is affected largely 
by the proximity to tractor owners because of the generally low mobility and sparsity of these tractors, as well as factors such as seasonality and simultaneity of demand (Takeshima et al. 2015b).

Lastly, we included dummy variables to control for sector (urban or rural), agroecological belt (Terai or other regions), administrative zone (within five development regions), and year-specific effects.

Most variables derived from the NLSS, but some variables were compiled from other sources.

We describe in more detail below how they were constructed in our analysis.

\section{Locations of Agricultural Research Stations}

Nepal conducts plant-breeding activities at various locations across the country. Although new varieties of major crops are cross-bred mainly at designated headquarters of the Nepal Agricultural Research Council (NARC) or within national crop research programs, some developed varieties as well as foreign varieties of certain crops go through field evaluations at research stations that often focus on other crops. Some university departments are also involved with plant breeding, although the extent of their activities is not clear. Table 4.1 summarizes the types of programs and institutions that are leading plant-breeding efforts.

Table 4.1 Key Nepali agricultural research stations used in the model

\begin{tabular}{ll}
\hline ARS type & Program, region, or institution \\
\hline National Agricultural Research & Eastern Development Region \\
Council (NARC) & Central Development Region \\
& Western Development Region \\
& Mid-Western Development Region \\
& Far-Western Development Region \\
\hline National research programs (for & Rice, Wheat, Maize, Grain Legumes, Oilseeds, Sugarcane, Citrus, Potato, Jute, \\
crops, livestock) & Ginger, Hill Crops, Bovine, Sheep and Goat, Swine, and Avian \\
\hline & Department of Plant Breeding, Institute of Agriculture and Animal Science \\
& (Tribhuvan University) \\
Universities & Kathmandu University, School of Science, Department of Biotechnology \\
& Purbanchal University \\
& Pokhara University \\
\hline
\end{tabular}

Source: Author's compilations based on NARC and secondary sources.

\section{Agroecological Data}

Various sets of spatial data on agroecological conditions have been obtained. Historical monthly rainfall data between 1970 and 2000 are available in a $0.5 \times 0.5$-degree grid from the CGIAR $^{3}$ Consortium for Spatial Information (2004). Using this dataset, we calculated the historical average and standard deviation of rainfall for each month in each VDC. We first identified which grid each VDC belonged to and then applied the values in the grid to that VDC. If the VDC straddled multiple grids, the grid that overlapped the largest area of the VDC was chosen.

Monthly solar irradiance figures were available for 2000, 2002, and 2003 in a 10-km grid from the Deutsches Zentrum für Luft- und Raumfahrt (DLR, 2004).

Soil data were obtained from FAO et al. (2012). The dominant soil type in each VDC was defined as the soil that covered the largest area within the VDC.

Terrain ruggedness and elevation were based on Global 30-Arc-Second (GTOPO30) data (U.S. Geological Survey, 1996). Ruggedness was calculated following the methods used in Riley, DeGloria, and Elliot (1999) and recent studies (Nunn and Puga 2012). The median values within each VDC were used.

3A global research partnership for a food secure future. 
Endowments of cultivable land were defined as the sum of cropped areas and pasture (Ramankutty et al. 2008) because pasture is relatively easily converted into farmland compared with forest (Binswanger and Donovan 1987). This figure was divided by the population of the corresponding VDC, interpolated from the population censuses of 1991, 2001, and 2011, in order to obtain cultivable land area per capita (Nepal CBS 1991, 2001, 2011b).

\section{Overall Household Profit $\Pi$}

The dependent variable we used in the matching estimations (PSM and GPSM) was household earned income, which is a proxy of household profit $\Pi$ in (1). Household earned income was measured by calculating household expenditures (including investments, net lending, and remittances sent), net of unearned income (including remittances received). Specifically, $\Pi$ consists of the following:

$\Pi \quad=$ annual household expenditure on nondurables (food and nonfood)

+ annual educational expenses (school fees)

+ health expenses

+ net purchase of agricultural equipment (= purchase of agricultural equipment - sales of agricultural equipment

+ expenditures on utilities (water, gas, electricity, firewood)

+ net rent payment for housing (= rent paid minus any rent received)

+ net credit lending (= (loan payment inclusive of interest rate - credit borrowed $)+$

(credit given out - amount paid back))

+ net asset rent paid

+ remittances sent

- remittances received.

The value of food consumption was assessed using quantities consumed multiplied by the market purchase prices (household-specific or district median). The food consumption reported by the NLSS was for seven days prior to the interview. Therefore, the amount was multiplied by $365 / 7$ to obtain the annual amount consumed. Similarly, expenditures on all other items were converted into annual figures whenever necessary. The real value of $\Pi$ was measured as kilograms of cereal, based on average local prices of rice and wheat.

Importantly, using the above definition, $\Pi$ corresponded to profit from not only agricultural activities but also nonfarm activities. Farm and nonfarm activities often substitute each other as a source of income for the household. Certain unobserved shocks, such as weather, might affect the substitution of within-household resource allocation across these activities. In such a case, limiting the outcome to profits from agricultural activities could cause the omitted variable bias, particularly if the shocks also affected the household's decision to use tractors. However, since off-farm income-earning activities are often employed to diversify such weather risks, combined income (farm and nonfarm) may be less susceptible to this type of unobserved shock.

\section{Samples Used}

In order to analyze the determinants of tractor hiring and related expenditures, we focused on households that owned farmland, as nonfarm households and nonlanded households are likely to have very different characteristics from landed households. In addition, we excluded households that owned tractors because their wealth characteristics are likely to be very different from those of the nonowner households. In addition, we excluded those observations that were missing information on household members' education level, access (travel time required to the nearest market, roads, and other major facilities), and soil types. Consequently, our sample consisted of 7,203 households, among which 1,316 rented tractors. Table 4.2 presents the descriptive statistics of variables used among the sample of farm households, after dropping outliers. 
Table 4.2 Descriptive statistics of variables used (raw data combining three rounds of the NLSS)

\begin{tabular}{|c|c|c|}
\hline Variable & Mean & SE \\
\hline Soil = Humic Acrisols (Ah) (default) & 0.04 & 0.21 \\
\hline Soil = Dystric Cambisols $(\mathrm{Bd})$ & 0.53 & 0.50 \\
\hline Soil = Eutric Fluvisols $(\mathrm{Je})$ & 0.35 & 0.47 \\
\hline Soil = Dystric Regosols $(\mathrm{Rd})$ & 0.08 & 0.27 \\
\hline Soil $=$ minor soil & 0.00 & 0.05 \\
\hline Rainfall (historical average) & $1,371.72$ & 260.46 \\
\hline Rainfall (historical standard deviation) & 589.56 & 91.15 \\
\hline Solar radiation index & 4432.20 & 388.80 \\
\hline Terrain ruggedness index & 293.59 & 267.80 \\
\hline Elevation (meter, VDC median) & 848.59 & 807.11 \\
\hline Per capita agricultural area (crop area + pasture area) (hectares [ha] per capita) & 0.20 & 0.33 \\
\hline Fertilizer manure endowments $(\mathrm{kg})$ & 52.56 & 44.19 \\
\hline Household size & 5.75 & 2.76 \\
\hline Household male member $\geq 20$ years old & 1.29 & 0.20 \\
\hline Household female member $\geq 20$ & 1.48 & 0.14 \\
\hline Household male member (16-19) & 0.23 & 0.07 \\
\hline Household female member (16-19) & 0.25 & 0.06 \\
\hline Household male member (11-15) & 0.29 & 0.07 \\
\hline Household female member (11-15) & 0.28 & 0.07 \\
\hline Household male member (5-10) & 0.43 & 0.12 \\
\hline Household female member (5-10) & 0.43 & 0.11 \\
\hline Gender of household head $(1=$ male, $0=$ female $)$ & 0.81 & 0.39 \\
\hline Literacy of household head ( $1=$ literate, $0=$ illiterate $)$ & 0.48 & 0.50 \\
\hline Average education levels of working-age household members & 3.07 & 2.96 \\
\hline Price of urea per $\mathrm{kg}(\mathrm{kg}$ of cereal) & 1.52 & 0.60 \\
\hline Price of DAP per $\mathrm{kg}(\mathrm{kg}$ of cereal) & 2.35 & 0.64 \\
\hline Real wage (daily wage, $\mathrm{kg}$ of cereal) & 10.72 & 3.48 \\
\hline Tractor rental cost per hour ( $\mathrm{kg}$ of cereal) & 44.34 & 11.84 \\
\hline Irrigation (share of farm households irrigating within the VDC) & 0.57 & 0.14 \\
\hline Whether credit was obtained in the previous year (yes $=1$ ) & 0.32 & 0.47 \\
\hline Whether formal credit was obtained in the previous year (yes $=1$ ) & 0.06 & 0.24 \\
\hline Land area owned (lowland, ha) & 0.44 & 0.92 \\
\hline Land area owned (upland, ha) & 0.34 & 0.80 \\
\hline Number of plots & 3.51 & 2.93 \\
\hline Real household asset value-excluding farmland, livestock, equipment ( $\mathrm{kg}$ of cereal) & $27,810.71$ & $103,059.4$ \\
\hline Real household asset value_farmland ( $\mathrm{kg}$ of cereal) & $62,948.80$ & $338,897.4$ \\
\hline Real household asset value-livestock ( $\mathrm{kg}$ of cereal) & $2,289.18$ & $2,012.21$ \\
\hline Real household asset value-equipment (kg of cereal) & 505.25 & $3,949.32$ \\
\hline Ownership of draft animals (bullock/cow, buffalo, horses/donkeys/mules) & 0.64 & 0.48 \\
\hline Travel time to the nearest bank (minutes) ${ }^{b}$ & 100.00 & $1,418.58$ \\
\hline Travel time to the nearest bus stop (minutes) ${ }^{b}$ & 45.00 & $1,805.35$ \\
\hline Travel time to the nearest market cooperatives (minutes) ${ }^{\mathrm{b}}$ & 60.00 & $2,583.48$ \\
\hline Travel time to the nearest market center (minutes) ${ }^{\mathrm{b}}$ & 80.00 & $1,385.93$ \\
\hline Travel time to the nearest paved road (minutes) ${ }^{b}$ & 90.00 & $1,418.58$ \\
\hline Travel time to the nearest retail shop (minutes) ${ }^{b}$ & 15.00 & $3,149.15$ \\
\hline Advanced caste in VDC (\%) ${ }^{\mathrm{a}}$ & 0.06 & 0.11 \\
\hline Nonindigenous population in VDC $(\%)^{a}$ & 0.31 & 0.21 \\
\hline Piped-in water as main source of drinking water $(1=$ yes $)$ & 0.40 & 0.49 \\
\hline Owns house $(1=$ yes $)$ & 0.98 & 0.15 \\
\hline Electricity the main source of light $(1=$ yes $)$ & 0.36 & 0.48 \\
\hline
\end{tabular}




\section{Table 4.2 Continued}

\begin{tabular}{|c|c|c|}
\hline Variable & Mean & SE \\
\hline Wood the main source of cooking fuel $(1=$ yes $)$ & 0.75 & 0.43 \\
\hline Access to garbage disposal service $(1=$ yes $)$ & 0.01 & 0.10 \\
\hline Uses garbage as fertilizer ( $1=$ yes $)$ & 0.69 & 0.46 \\
\hline Sector $($ urban $=0$, rural $=1)$ & 0.02 & 0.24 \\
\hline Households owning tractors within VDC $(\%)(\text { sample mean })^{c}$ & 0.65 & 2.31 \\
\hline Soil similarity with research stations & 0.84 & 0.37 \\
\hline Difference in standard deviation of rain & 14.55 & 24.07 \\
\hline Real household earned income ( $\mathrm{kg}$ of cereal) & $14,156.25$ & $19,744.53$ \\
\hline
\end{tabular}

Source: Authors' estimations.

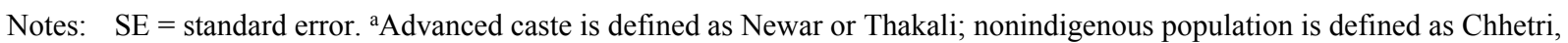

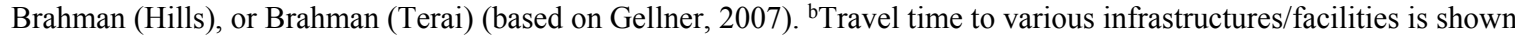
as a median owing to the highly skewed distribution. ${ }^{\circ}$ Equals 100 if all households own tractors. 


\section{EMPIRICAL RESULTS}

\section{Determinants of Decisions to Rent Tractors and How Much to Pay for Such Rentals}

Before we conducted the series of matching estimators described above, we briefly assessed the determinants of decisions to rent tractors and how much to pay for them. We based the estimators on Heckman's (1979) sample selection model, extended to include pseudo-panel specifications that incorporated correlated random effects.

Table 5.1 summarizes the determinants of (a) probability that a farm household adopts hired tractors and (b) growth rate of expenditures on hired tractors upon adoption. The figures represent marginal effects evaluated using the means of all explanatory variables. For example, a 1-hectare increase in the lowland farm area owned by a farm household led to a 0.45 percent increase in the probability that the household rents tractors, holding other factors constant, including the availability and cost of labor. The number of observations is smaller in column (b) because, as Heckman's model prescribes, it was restricted to those who actually adopted hired tractors.

Table 5.1 Determinants of tractor use based on Heckman's (1979) maximum likelihood estimation model, extended to include pseudo-panel-correlated random effects

\begin{tabular}{|c|c|c|c|c|}
\hline \multirow{2}{*}{$\begin{array}{l}\text { Explanatory variables } \\
\text { Rainfall (historical average, } \mathrm{mm} \text { ) }\end{array}$} & \multicolumn{2}{|c|}{$\begin{array}{l}\text { (a) Probability (\%) } \\
\text { of adopting hired } \\
\text { tractors }\end{array}$} & \multicolumn{2}{|c|}{$\begin{array}{l}\text { (b) Growth rate of real } \\
\text { annual expenditures for } \\
\text { hired tractors upon } \\
\text { adoption }\end{array}$} \\
\hline & 0.035 & $(0.030)$ & $0.010^{* * *}$ & $(0.003)$ \\
\hline Rainfall (historical standard deviation, $\mathrm{mm}$ ) & 0.031 & $(0.067)$ & $-0.013^{*}$ & $(0.008)$ \\
\hline Average solar radiation index & 0.002 & $(0.002)$ & 0.000 & $(0.000)$ \\
\hline Terrain ruggedness index & $-0.012^{\star \star \star}$ & $(0.003)$ & 0.000 & $(0.001)$ \\
\hline Elevation (VDC median, $\mathrm{m}$ ) & $-0.003^{* *}$ & $(0.001)$ & 0.000 & $(0.000)$ \\
\hline $\begin{array}{l}\text { Agricultural land per capita within VDC }(10,000 \text { hectares [ha] } \\
\text { per capita) }\end{array}$ & 0.385 & $(2.347)$ & $-0.484^{* *}$ & $(0.239)$ \\
\hline Household size & -0.215 & $(0.202)$ & 0.008 & $(0.028)$ \\
\hline Household male member $\geq 20$ years old & -0.340 & $(0.323)$ & 0.017 & $(0.043)$ \\
\hline Household female member $\geq 20$ & $0.652^{*}$ & $(0.383)$ & 0.058 & $(0.051)$ \\
\hline Household male member (16-19) & -0.511 & $(0.389)$ & 0.057 & $(0.053)$ \\
\hline Household female member (16-19) & -0.601 & $(0.385)$ & 0.058 & $(0.054)$ \\
\hline Household male member (11-15) & $0.638^{*}$ & $(0.354)$ & -0.051 & $(0.047)$ \\
\hline Household female member (11-15) & 0.333 & $(0.369)$ & 0.034 & $(0.050)$ \\
\hline Household male member (5-10) & $-0.537^{*}$ & $(0.323)$ & -0.058 & $(0.045)$ \\
\hline Household female member $(5-10)$ & -0.095 & $(0.365)$ & -0.043 & $(0.047)$ \\
\hline Household head gender $($ female $=1$ ) & -0.173 & $(0.440)$ & 0.085 & $(0.063)$ \\
\hline Household head literate $(y e s=1$ ) & $1.173^{* * *}$ & $(0.453)$ & 0.084 & $(0.059)$ \\
\hline Average years of education (working-age member) & 0.032 & $(0.071)$ & 0.015 & $(0.010)$ \\
\hline Real price of urea & -0.070 & $(0.246)$ & 0.014 & $(0.020)$ \\
\hline Real price of DAP & -0.290 & $(0.409)$ & $0.126^{* * *}$ & $(0.047)$ \\
\hline Real wage (daily wage) (kg of cereals) & 0.014 & $(0.073)$ & $0.020^{*}$ & $(0.011)$ \\
\hline $\begin{array}{l}\text { Real tractor rental price per hour reported in the community } \\
\text { survey }\end{array}$ & -0.016 & $(0.020)$ & 0.003 & $(0.003)$ \\
\hline Farmers within VDC irrigating (\%) & 0.019 & $(0.018)$ & 0.001 & $(0.002)$ \\
\hline Whether credit was obtained in previous year (yes $=1$ ) & 0.005 & $(0.005)$ & -0.001 & $(0.001)$ \\
\hline Whether formal credit was obtained in previous year (yes $=1$ ) & 0.008 & $(0.007)$ & 0.001 & $(0.001)$ \\
\hline Land area owned (lowland, ha) & $0.449^{*}$ & $(0.240)$ & $0.162^{* * *}$ & $(0.036)$ \\
\hline Land area owned (upland, ha) & -0.742 & $(0.580)$ & 0.112 & $(0.094)$ \\
\hline
\end{tabular}


Table 5.1 Continued

\begin{tabular}{|c|c|c|c|c|}
\hline \multirow{2}{*}{$\begin{array}{l}\text { Explanatory variables } \\
\text { Number of owned farm plots }\end{array}$} & \multicolumn{2}{|c|}{$\begin{array}{l}\text { (a) Probability (\%) } \\
\text { of adopting hired } \\
\text { tractors }\end{array}$} & \multicolumn{2}{|c|}{$\begin{array}{l}\text { (b) Growth rate of real } \\
\text { annual expenditures for } \\
\text { hired tractors upon } \\
\text { adoption }\end{array}$} \\
\hline & 0.024 & $(0.089)$ & 0.012 & $(0.012)$ \\
\hline Ln (real asset value of farmland) & $0.949^{* * *}$ & $(0.230)$ & $0.134^{* * *}$ & $(0.031)$ \\
\hline Ln (real asset value of livestock) & $0.202^{* * *}$ & $(0.076)$ & $0.025^{* *}$ & $(0.012)$ \\
\hline Ln (real asset value of farm equipment) & $0.304^{* * *}$ & $(0.104)$ & $0.027^{*}$ & $(0.014)$ \\
\hline Ln (real asset value of other assets) & 0.162 & $(0.133)$ & 0.025 & $(0.022)$ \\
\hline Owns draft animal (yes $=1$ ) & -0.005 & $(0.007)$ & 0.000 & $(0.001)$ \\
\hline Ln (minutes to travel to the nearest bank) & -0.053 & $(0.339)$ & -0.005 & $(0.051)$ \\
\hline Ln (minutes to travel to the nearest bus stop) & 0.179 & $(0.310)$ & 0.022 & $(0.040)$ \\
\hline Ln (minutes to travel to the nearest cooperatives) & -0.145 & $(0.299)$ & 0.047 & $(0.042)$ \\
\hline Ln (minutes to travel to the nearest market center) & -0.380 & $(0.335)$ & $-0.121^{* *}$ & $(0.051)$ \\
\hline Ln (minutes to travel to the nearest paved road) & $-0.478^{*}$ & $(0.283)$ & 0.027 & $(0.039)$ \\
\hline Ln (minutes to travel to the nearest shop) & -0.191 & $(0.332)$ & 0.020 & $(0.041)$ \\
\hline Advanced caste (sample share within VDC) (\%) & 0.063 & $(0.040)$ & 0.003 & $(0.006)$ \\
\hline Nonindigenous population (sample share within VDC) (\%) & -0.001 & $(0.035)$ & -0.002 & $(0.006)$ \\
\hline Piped-in water as main source of drinking water $(1=$ yes $)$ & -0.700 & $(0.657)$ & -0.052 & $(0.101)$ \\
\hline Owns house ( 1 = yes $)$ & -1.932 & $(1.454)$ & -0.298 & $(0.264)$ \\
\hline Electricity the main source of light $(1$ = yes $)$ & $1.911^{* * *}$ & $(0.583)$ & $0.153^{* *}$ & $(0.069)$ \\
\hline Wood the main source of cooking fuel $(1=$ yes $)$ & -0.712 & $(0.446)$ & -0.032 & $(0.054)$ \\
\hline Access to garbage disposal services & -1.519 & $(1.100)$ & $-0.424^{* *}$ & $(0.170)$ \\
\hline Uses garbage for fertilizer & -0.327 & $(0.430)$ & 0.021 & $(0.061)$ \\
\hline Sector (rural = 1) & 0.290 & $(0.867)$ & -0.016 & $(0.103)$ \\
\hline Similarity of soils to ARS-located areas & $2.009^{*}$ & $(1.106)$ & 0.167 & $(0.177)$ \\
\hline $\begin{array}{l}\text { Farm households owning tractors within VDC (\%) (sample } \\
\text { mean) }\end{array}$ & $0.531^{* *}$ & $(0.236)$ & $0.049^{*}$ & $(0.027)$ \\
\hline $\begin{array}{l}\text { Farm households owning tractors within VDC (\%) (sample } \\
\text { mean)* in the Terai }\end{array}$ & $-0.599^{* *}$ & $(0.251)$ & $-0.052^{*}$ & $(0.029)$ \\
\hline District time average & & cluded & & cluded \\
\hline Region, agroecological belt dummy & & ncluded & & cluded \\
\hline Year dummy & & hcluded & & cluded \\
\hline Soil dummy & & ncluded & & cluded \\
\hline Constant & & hcluded & & cluded \\
\hline Number of observations & & 7,203 & & 1,316 \\
\hline$p$ value ( $H_{0}$ : coefficients are jointly insignificant) & & 0.000 & & 0.000 \\
\hline
\end{tabular}

Source: Authors' estimations.

Notes: $* 10 \% ; * * \% ; * * * 1 \%$. ${ }^{\text {an }}$ Numbers are marginal effects on (a) the probability (\%) of renting tractors or (b) the growth rate

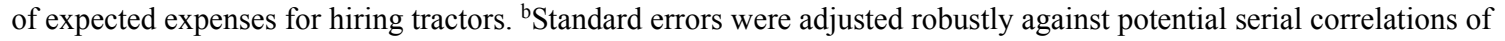
idiosyncratic error terms within the VDC. Probit and related pseudo-maximum likelihood estimators generally remained consistent (though inefficient) when serial correlation was present (Poirier and Ruud 1988).

The set of statistically significant determinants was generally consistent with the economic theory of agricultural mechanization, although some determinants appeared rather contradictory. For example, a larger lowland area owned was correlated with both the adoption and intensive use of hired tractors. However, similar effects were not observed for the size of upland owned, indicating that the demand for rented tractors is particularly strong in the lowlands. Conditional on the size of farmland owned, the higher value of such land was associated with a greater use of hired tractors. This finding is consistent with the hypothesis that more valuable land is more intensively cultivated and, as a result, the demand for tractor use may be higher. Greater holdings of livestock and farm equipment likewise seemed to encourage the use of hired tractors, either because of the need to intensively grow feed crops or the 
availability of complementary equipment to raise the returns on mechanized land preparation and transport. Having electricity as the main source of lighting in the house released household members from generating alternative sources of light and increased the availability of household members to meet the greater labor needs (such as weeding, planting, and harvesting) that follow mechanized land preparation. Similarly, a larger household - particularly with many adult female household members or young teenage male members - may have been more likely to rent tractors because family labor was able to complement tractors in carrying out subsequent farming activities. In addition, these factors also may have affected the shadow wages of household members (Jacoby 1993), although the mechanisms by which wages were affected were rather complicated and cannot be examined in a short paper such as this. Similarly, higher real wages within an area led to more intensive use of hired tractors. Furthermore, the differential effects of the endowments of different types of household members were consistent with the possibility that labor is imperfectly substitutable across types.

Chemical fertilizers may become substitutes for tractor use-particularly upon the adoption of tractors. This is true possibly because fertilizing is a relatively land-saving technology, whereas tractor use is a labor-saving technology. This explanation applies to the positive effect that higher DAP prices had on the expenses of tractors.

The adoption of hired tractors was discouraged in areas with more rugged terrain and higher elevations because greater ruggedness may raise the costs of tractor movement between farms.

Nonindigenous households tended to spend more resources on tractor services upon their adoption, suggesting heterogeneous effects across different ethnicities. Greater rainfall induced intensive tractor use, but greater rainfall variability discouraged it, consistent with how risk-averse farmers tend to avoid using modern technologies that often increase risk. Better access to the nearest market center and a paved road all encouraged the adoptions of hired tractors.

Importantly, a greater share of tractor owners within the VDC encouraged both adoption and larger expenditures on hired tractors in the Hills and Mountains, suggesting that access to tractors within the vicinity may have influenced the adoption and use of hired tractors, although this effect seemed to disappear in the Terai. This finding is consistent with the limited spatial mobility of tractors and geographical coverage of tractor hiring services (observed in Nigeria, where similarly four-wheel tractors provide most tractor services through custom hiring) (Takeshima et al. 2015b).

Although these analyses addressed the estimate bias due to farmers' self-selection of whether or not to adopt hired tractors, biases may have persisted owing to the potential endogeneity of certain variables included in both stages, such as ownership of assets that may be relatively variable (for example smaller agricultural equipment) and the use of certain primary sources of fuel, electricity, or water. Although credit acquisitions occurred in previous years and were unlikely to have been influenced by current tractor hiring decisions, certain unobserved household-specific fixed effects may have affected both of these factors. If so, the results may have run into an endogeneity problem. Thus, future studies are needed to further investigate these issues.

\section{Income Effects of Rented Tractor Adoptions}

\section{Effects of Rented Tractor Adoptions: Extensive Margin}

We now turn to the estimated ATTs for the various groups of farm households. Table 5.2 presents estimated ATTs using different thresholds and matching methods. The ATTs here measure the average percentage increases in real household income (measured as expenditures) owing to the use of rented tractors, among those who actually rented tractors. ${ }^{4}$ For example, 0.122 indicates that, on average, farm households who could rent tractors enjoyed a 12.2 percent increase in overall household expenditures because of renting in tractors.

\footnotetext{
${ }^{4}$ Because the estimates were for ATT and not average treatment effect (ATE), we could not infer that the estimated figure was the effect from renting in tractors for households that were currently not renting.
} 
Table 5.2 Estimated wedges due to imperfections in the tractor hiring market in the Terai region of Nepal (\% differences in per capita real expenditures)

\begin{tabular}{|c|c|c|c|c|c|c|}
\hline \multirow[t]{2}{*}{ Data type } & \multirow{2}{*}{$\begin{array}{l}\text { Tractor } \\
\text { expenditure } \\
\text { threshold } \\
\text { (kg of cereal) }\end{array}$} & \multicolumn{5}{|c|}{ Matching method } \\
\hline & & $\begin{array}{c}\text { PSM- } \\
\text { nearest } \\
\text { neighbor^ }\end{array}$ & $\begin{array}{c}\text { PSM- } \\
\text { nearest } \\
\text { neighbor }\end{array}$ & $\begin{array}{c}\text { PSM- } \\
\text { nearest } \\
\text { neighbor } \\
\text { with caliper } \\
(0.01)^{\wedge}\end{array}$ & $\begin{array}{c}\text { PSM- } \\
\text { nearest } \\
\text { neighbor } \\
\text { with caliper } \\
(0.01)^{\#}\end{array}$ & $\begin{array}{c}\text { Mahalanobis } \\
\text { bias-adjusted } \\
\text { covariate } \\
\text { matching } \\
\text { neighbor \# }\end{array}$ \\
\hline \multirow[t]{4}{*}{$\begin{array}{l}\text { Cross-section } \\
\text { matching }\end{array}$} & 100 & $\begin{array}{c}0.048 \\
(0.091)\end{array}$ & $\begin{array}{c}0.006 \\
(0.073)\end{array}$ & $\begin{array}{c}0.081 \\
(0.085)\end{array}$ & $\begin{array}{c}0.020 \\
(0.072)\end{array}$ & $\begin{array}{c}0.077 \\
(0.072)\end{array}$ \\
\hline & 150 & $\begin{array}{c}0.086 \\
(0.076)\end{array}$ & $\begin{array}{c}0.094 \\
(0.062)\end{array}$ & $\begin{array}{c}0.120 \\
(0.076)\end{array}$ & $\begin{array}{c}0.123^{\star} \\
(0.063) \\
{[1.16]}\end{array}$ & $\begin{array}{l}0.109 * \\
(0.063)\end{array}$ \\
\hline & 200 & $\begin{array}{c}0.121 \\
(0.075)\end{array}$ & $\begin{array}{c}0.115^{\star} \\
(0.061) \\
{[1.25]}\end{array}$ & $\begin{array}{c}0.140 * \\
(0.074) \\
{[1.16]}\end{array}$ & $\begin{array}{c}0.113^{*} \\
(0.062) \\
{[1.23]}\end{array}$ & $\begin{array}{l}0.115^{\star} \\
(0.059)\end{array}$ \\
\hline & 250 & $\begin{array}{c}0.039 \\
(0.067)\end{array}$ & $\begin{array}{c}0.105^{\star} \\
(0.059) \\
{[1.18]}\end{array}$ & $\begin{array}{c}0.034 \\
(0.070)\end{array}$ & $\begin{array}{c}0.094 \\
(0.060)\end{array}$ & $\begin{array}{l}0.122^{* *} \\
(0.057)\end{array}$ \\
\hline $\begin{array}{l}\text { DID matching } \\
\text { based on } \\
\text { panel data }^{b}\end{array}$ & 250 & $\begin{array}{l}-0.063 \\
(0.145)\end{array}$ & $\begin{array}{l}-0.010 \\
(0.123)\end{array}$ & $\begin{array}{l}-0.038 \\
(0.157)\end{array}$ & $\begin{array}{l}-0.018 \\
(0.130)\end{array}$ & $\begin{array}{l}-0.049 \\
(0.138)\end{array}$ \\
\hline
\end{tabular}

Source: Authors' estimations.

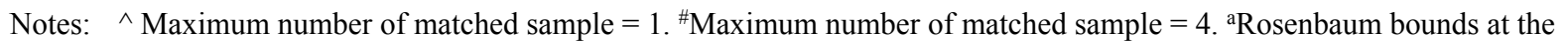
critical gamma are shown in brackets [ ] based on nonadjusted matching from psmatch2 if the nonadjusted estimate was not statistically significantly different from the bias-adjusted estimates. This is because Stata runs a Rosenbaum bounds test only after the psmatch 2 command. ${ }^{b}$ For the panel data, we used a caliper of 0.05 instead of 0.01 in order to retain efficiency in the estimates. $* 10 \% ; * * 5 \% ; * * * 1 \%$.

The average income effects of marginally renting in tractors were ambiguous. When only marginal adopters whose tractor rental spending did not exceed $100 \mathrm{~kg}$ of cereals were considered, income effects were statistically insignificant under all matching methods. As the threshold of tractor rental expenditures was raised, however, we started obtaining statistically significant effects, depending on the matching methods used. For example, by applying DID-PSM to the panel data, estimated average income effects were generally less positive than for cross-section data, although they were all statistically insignificant mainly because of the small sample size used to obtain panel data. Overall, estimated income effects may not have been significantly strong for all the households to make the average effects statistically significant.

\section{The Balancing Property of Samples in Propensity Score Matching}

In order to improve the balancing properties of the matched sample, a fraction of samples were excluded from the matching estimation using the following criteria: samples in the control (treated) group were excluded if at least one of the independent variables was larger (smaller) than the maximum (minimum) values of independent variables in the treated (control) group. This procedure ensured sufficient balancing properties in the remaining samples while minimizing the excluded samples. When this procedure was applied to the sample with a tractor expenditure threshold of $250 \mathrm{~kg}$ of cereal, approximately 30 percent of the samples were excluded. The estimated matched samples achieved sufficient balancing properties in terms of the differences in covariate means, since less than 10 percent of covariates exhibited a statistically significant difference in means across groups at a 10 percent significance level (Table 5.3). Cross-section data also satisfied Rubin's B (Cochran and Rubin 1973) as being less than 0.4, with which, according to Rubin (2001), "the differences between treatment and control groups [...] are [...] arguably minor enough." Rubin's B for the panel data was slightly higher than 0.4 , and therefore, the results may need to be interpreted with caution. It also satisfied an additional condition of $0.5 \leq$ Rubin's $R \leq 2$, which 
is necessary for sufficiently balanced properties (Rubin 2001). Figure 5.1 depicts the distributions of the propensity score for the treated (renting in tractors) and control (not renting in tractors) groups among households that did not own tractors.

Table 5.3 Balancing sample properties using propensity score matching

\begin{tabular}{lcc}
\hline Categories & Cross-section & Panel \\
\hline Rubin's B & 0.32 & 0.45 \\
Rubin's R & 0.92 & 0.64 \\
Percentage of covariates with statistically & 8 & 0 \\
significant mean differences at 10 percent & & \\
\hline
\end{tabular}

Source: Authors' estimations.

Figure 5.1 Distribution of estimated propensity scores by tractor use status among households not owning tractors in the Terai region of Nepal

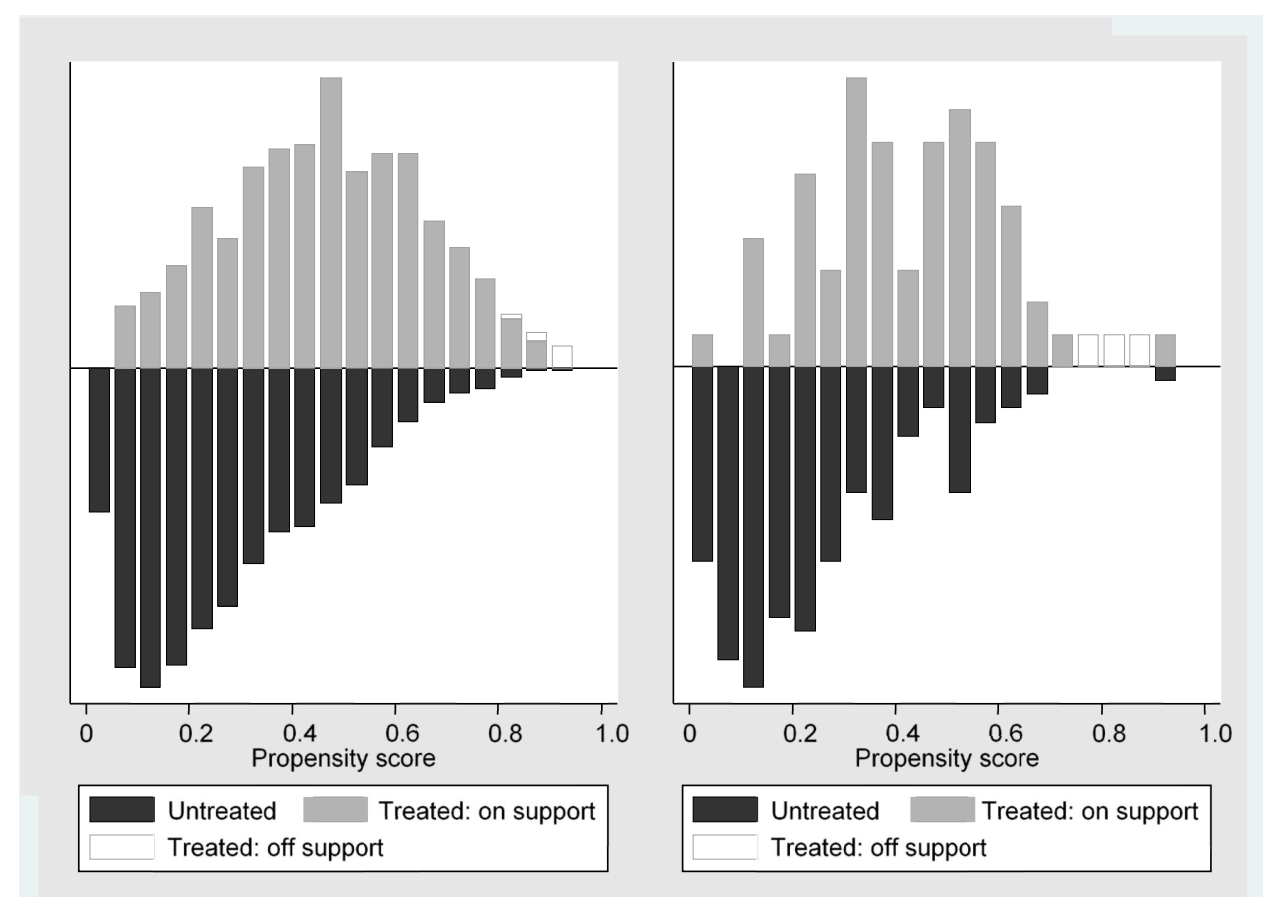

Source: Authors' estimations.

Notes: $\quad$ Treated $=$ renting in tractors; Untreated $=$ not renting in tractors. Left figure $=$ cross-section data; Right figure $=$ panel data.

\section{Heterogeneity of Income Effects of Renting in Tractors}

The effects of renting in tractors presented in Table 5.2 are averaged across all relevant samples and do not account for the potential heterogeneity in the effects across samples. Given the heterogeneous socioeconomic characteristics of farm households, the effects of tractor adoption can also vary across them.

One way to assess such potential variations in these effects is by estimating heterogeneous treatment effects (HTEs) (Xie et al. 2012), that is, the relationship between the treatment effects and the household's propensity score for renting in tractors. We estimated the HTE for household spending on tractor rental ( $\leq 250 \mathrm{~kg}$ worth of cereal) using the command hte (Jann, Brand, and Xie 2010). 
For both cross-section data and panel data, Figure 5.2 plots the treatment effects (the impact of renting in tractors on household earned income) that were conditional on the propensity of renting in tractors, as well as their 90 percent confidence intervals. These were based on the local polynomial regressions estimated using the Matching-Smoothing Method proposed by Xie et al. (2012).

Generally, the level of treatment effects as well as their statistical significance varies depending on the propensity scores. This indicates that the income effect of renting in tractors varies across farm households, depending on their propensity to rent in tractors. In the cross-section data, statistically significantly positive effects were found among households with higher propensity scores, although the effects seemed significant for a relatively wide range of propensity scores $(0.3-0.7)$. In the panel data, statistically significant positive effects seemed to be concentrated among those with high propensity scores $(>0.6)$. The DID-PSM based on the panel data was more consistent because it further eliminated biases due to unobserved household-specific fixed effects; however, the PSM based on cross-section data was likely more efficient given the larger sample size. The PSM with cross-section data also achieve slightly better balancing properties. Overall, at least some segment of the population in the Terai experienced a significant increase in household income from the marginal adoption of tractors. It is therefore likely that a certain share of farm households in the Terai are facing some constraints for renting in tractors, while a substantial share of households are not similarly constrained.

\section{Figure 5.2 Heterogeneous effects of tractor adoption on earned income and cumulative distribution of propensity scores to rent in tractors in the Terai region of Nepal, 2010}

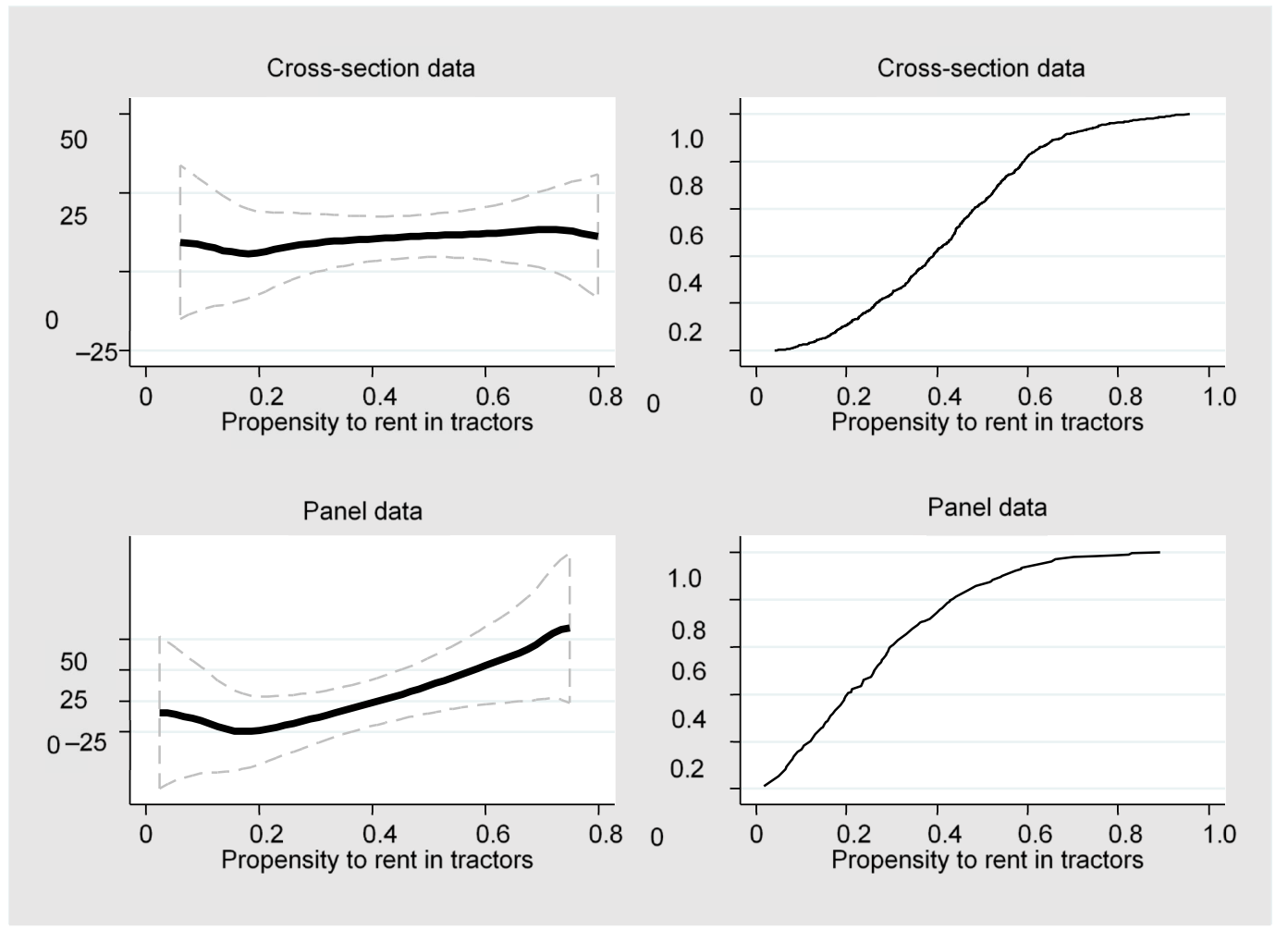

Source: Authors' estimations.

Notes: Left: Heterogeneous effects of tractor adoption on earned income, differentiated by the propensity to adopt tractor rental in the Terai. Solid lines and dashed lines represent the estimated treatment effects and their $90 \%$ confidence intervals, respectively. Vertical axis measures the change in earned income (\%). Right: Cumulative distribution of propensity scores to rent in tractors in 2010 (among nonowners of tractors) in the Terai. Vertical axis measures the cumulative share of farm households. 


\section{Effects of Rented Tractor Adoptions: Intensive Margin}

The thresholds used in Table 5.2 were intended to exclude households who might benefit more from potential scale effects realized through intensive tractor use. This was done in an attempt to separate the effects of hired tractor accessibility from the scale effects accruing to tractor use intensity. A question remains, however, as to whether the significant effects of adopting hired tractors seen in Table 5.2 and Figure 5.2 were in fact the effects of overcoming accessibility constraints. If these data were also capturing scale effects, as discussed above, we cannot conclude that they captured the effects of hired tractor accessibility. We investigated this question by examining whether substantial profit effects resulted from increasing tractor use intensity up to given thresholds, using GPSM. We used $250 \mathrm{~kg}$ of cereal as the expenditure threshold for tractor use intensity. By showing that the effects of treatment intensity were absent up to the expenditure threshold for rented tractors of $250 \mathrm{~kg}$ cereal, we could attribute all significant effects in the PSM (Table 5.2) to marginal adoption.

The balancing properties that must be satisfied in order for GPSM results to be consistent were assessed based on Takeshima (2015a). We found that approximately 4 percent of the absolute values of $t$ statistics exceeded 1.96, as expected under the null hypothesis that the means of $X \mathrm{~s}$ are jointly equal across groups, suggesting that the balancing properties given GPS were satisfied. Analyses were conducted on the 553 farm households who hired in tractors for not more than the equivalent of $250 \mathrm{~kg}$ of cereals.

Table 5.4 shows the results of regressions in which the natural log of real income was regressed on the functions of GPS and treatment $T$ (expenditure on rented tractors). As in Hirano and Imbens (2004), the coefficients in these regressions have no real meaning, but the statistical significance of the coefficients for GPS indicates that estimations of the treatment effects on outcomes are biased if GPS is excluded. In all the major specifications, we found that GPS was statistically significant, indicating that assessing the effects of tractor use intensity through GPSM reduces biases.

Table 5.4 Conditional expectations of outcomes estimated using generalized propensity scores (cross-section data) in the Terai region of Nepal

\begin{tabular}{lccc}
\hline Dependent variables & \multicolumn{2}{c}{ In (real expenditures net of unearned income) } \\
\hline Threshold & $\mathbf{2 5 0}$ & $\mathbf{2 5 0}$ & $\mathbf{2 5 0}$ \\
\hline$T$ & $-0.001(0.001)$ & $-0.004(.003)$ & $0.004(0.008)$ \\
GPS & $-6.982^{* * *}(2.205)$ & $-15.551^{* *}(6.250)$ & $3.906(18.456)$ \\
$T^{*}$ GPS & $0.084^{* *}(0.018)$ & $0.089^{* * *}(0.019)$ & $0.104^{* * *}(0.022)$ \\
$T^{2}$ & & $9.84 \mathrm{e}-06(0.000)$ & $-0.00007(0.00007)$ \\
$T^{3}$ & & & $2.00 \mathrm{e}-07(1.71 \mathrm{e}-07)$ \\
GPS $^{2}$ & & $67.722(43.392)$ & $-321.097(318.851)$ \\
GPS $^{3}$ & & & $2,003.315(1,648.068)$ \\
Constant & $9.423^{* * *}(0.153)$ & $9.713^{* * *}(0.221)$ & $9.309^{* * *}(0.339)$ \\
\hline$R^{2}$ & 0.094 & 0.100 & 0.104 \\
Number of observations & 553 & 553 & 553 \\
$H_{0}$ : jointly insignificant & 0.000 & 0.000 & 0.000 \\
\hline
\end{tabular}

Source: Authors' estimations.

Notes: ${ }^{a}$ Numbers in parentheses indicate the standard errors of estimated coefficients. $T=$ treatment level (real expenditures on tractor services hired in); GPS = generalized propensity score.

The left panel in Figure 5.3 illustrates how real household income is affected by the intensity of hired tractor use in both the Hills and Mountains and the Terai, estimated using GPSM. The right panel in Figure 5.3 illustrates the marginal treatment effects. In both panels, the top and bottom dashed lines indicate $90 \%$ confidence intervals. The left panel indicates that the intensity of hired tractor use generally has little effect on household income for tractor use expenditures equivalent to $\leq 250 \mathrm{~kg}$ of cereals. The right panel suggests that accumulated marginal income effects are not statistically significant for tractor use expenditures worth $\leq 250 \mathrm{~kg}$ of cereals. 
Figure 5.3 Insignificant income effects of tractor rental intensity for annual tractor rental expenses equivalent to $\leq \mathbf{2 5 0} \mathrm{kg}$ of cereals

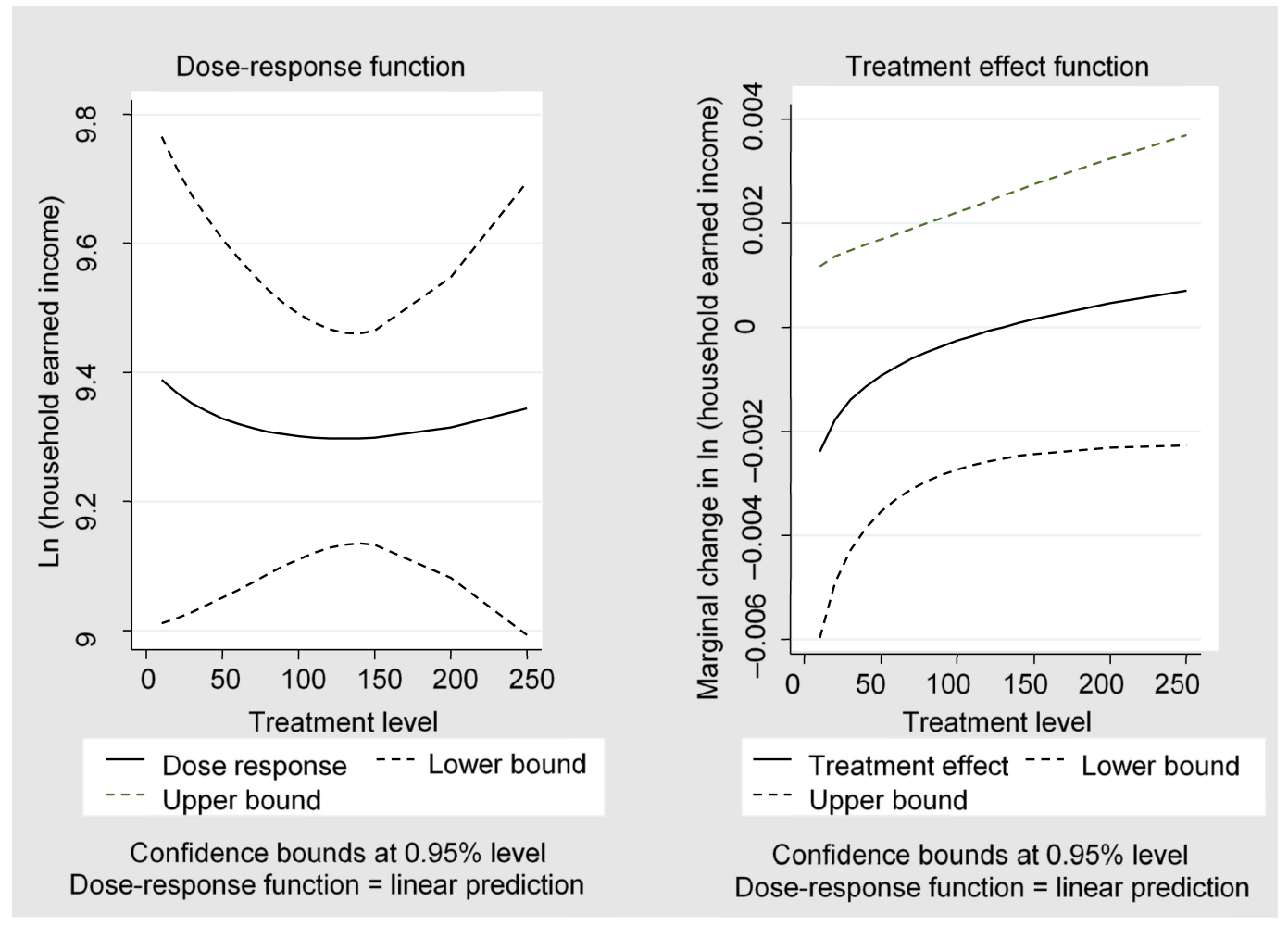

Source: Authors' estimations.

Notes: Horizontal axes shows the annual expenditures on tractor services, measured in kilograms of cereals. The lower and upper bounds were estimated based on 100 bootstrap estimates.

Combining the results shown in Figure 5.3, we can attribute statistically significant income effects to the adoption of hired tractors, as seen in Table 5.2 and Figure 5.2, and specifically to the effects arising from whether or not they were adopted rather than how intensively they were adopted (that is, the scale effects realized from the intensive use of hired tractors). It is important to note that Figure 5.3 illustrates the intensity effect upon the adoption of hired tractors. When there is no intensity effect, marginal income effects become insignificant, as in Figure 5.3, even though the adoption itself has statistically significant income effects, as seen in Table 5.2. It is important that readers not be confused by the findings of significant effects using PSM and insignificant effects using GPSM. The findings differ because GPSM focuses on treatment effects with respect to the intensity of treatment upon receiving the treatment and does not concern itself with the effects of receiving treatment itself (extensive margin), which PSM measures. 


\section{CONCLUSIONS AND KEY POLICY IMPLICATIONS}

The empirical findings discussed herein have significant implications. In the Nepal Terai, the current tractor hiring market seems relatively efficient, and substitutes for tractors (human and animal labor, for example) are relatively accessible. Thus, the lack of access to tractor hiring is generally not severe and not a binding constraint on increasing the incomes of many farm households. In these circumstances, tractor use is likely to result from the profit-maximizing behavior of households, given the production environment, and further direct intervention into tractor markets may not improve the welfare of households. If the tractor hiring market is in fact efficient, it is in line with recent evidence from China (Zhang et al. 2015) as well as some South Asian countries. That is, while individual tractor ownership can guarantee timely accessibility to tractors, emerging tractor hiring services can significantly reduce the cost of tractor services for nonowners through specialization.

However, evidence also indicates that heterogeneity among farm households is possible, and insufficient accessibility to hired tractors is still a binding constraint on some segment of farm households; solely relaxing such constraints is likely to yield benefits worth more than 10 percent of overall household income for this segment (excluding the potential scale benefits of intensive use of tractors). Thus, enhanced agricultural mechanization policies will play an important role in unleashing income growth for these farm households.

It is important to note that, even in areas where the tractor rental market is relatively efficient, such efficiency might be attributable to mechanization policies as much as to the private sector's efforts to improve efficiency. Further studies are needed to identify helpful policies so that they can be maintained.

In addition, the current analyses focused only on the marginal adoption of tractors. Therefore, further studies are needed to better understand the benefits arising from the scale effects of tractors. A recent study (Takeshima 2015c) investigated whether the adoption of hired tractors significantly affects the overall returns to scale in agricultural production. Although the close association between mechanization and rising returns to scale in agricultural production has been documented (Hayami and Ruttan 1985), the causal effects have not been formally established in the literature. Preliminary results from Takeshima (2015c) indicate that the adoption of hired tractors may be raising the returns to scale in agriculture in Nepal. If such effects are formally shown, the effects of mechanization may be more multifaceted than previously thought. The mechanization effects at the intensive margin are likely to be substantial compared with those at the extensive margin, on which the current study has focused. 


\section{REFERENCES}

Abadie, A., and G. W. Imbens. 2012. Matching on the Estimated Propensity Score. Cambridge, MA: Harvard University and National Bureau of Economic Research. Accessed December 23, 2015. www.hks.harvard.edu/fs/aabadie/pscore.pdf.

Abowd, J., and H. Farber. 1982. "Job Queues and the Union Status of Workers." Industrial and Labor Relations Review 35: 354-367.

Bellemare, M. F. and C. B. Barrett. 2006. "An Ordered Tobit Model of Market Participation: Evidence from Kenya and Ethiopia." American Journal of Agricultural Economics 88 (2): 324-337.

Binswanger H. 1986. “Agricultural mechanization: A Comparative Historical Perspective.” World Bank Research Observer 1: 27-56.

Binswanger, H., and G. Donovan. 1987. Agricultural Mechanization: Issues and Options. Washington, DC: World Bank.

Chamberlain, G. 1984. Panel Data. In Handbook of Econometrics, Vol. 2, edited by Z Grilliches and M. D. Intriligator, 1247-1318. Amsterdam: North-Holland.

CGIAR-CSI (CGIAR Consortium for Spatial Information). 2004. CRU TS 2.1 Rainfall data. Accessed December 24, 2015. http://csi.cgiar.org/cru/SELECTION/inputCoord.asp.

Cochran, W. G., and D. B. Rubin. 1973. "Controlling Bias in Observational Studies: A Review." Sankhyā: The Indian Journal of Statistics, Series A 35 (4): 417-446.

CSAM (Center for Sustainable Agricultural Mechanization). 2014. “Country Pages.” Accessed July 2, 2014. http://uncsam.org/cp index.htm.

Diao, X., F. Cossar, N. Houssou, and S. Kolavalli. 2014. "Mechanization in Ghana: Emerging Demand, and the Search for Alternative Supply Models." Food Policy 48: 168-181.

DiPrete, T., and M. Gangl. 2004. "Assessing Bias in the Estimation of Causal Effects: Rosenbaum Bounds on Matching Estimators and Instrumental Variables Estimation with Imperfect Instruments.” Sociological Methodology 34: 271-310.

DLR (Deutsches Zentrum für Luft- und Raumfahrt). 2004. "Solar: Monthly and Annual Average Global Horizontal (GHI) GIS Data at 10km Resolution for Nepal from DLR.” Accessed December 24, 2015. http://en.openei.org/datasets/dataset/solar-monthly-and-annual-average-global-horizontal-ghi-gis-data-at10km-resolution-for-nepal-from.

Evenson, R., and L. E. Westphal. 1995. "Technological Change and Technology Strategy.” In Handbook of Development Economics, edited by J. Behrman and T.N. Srinivasan, 2209-2299. Amsterdam: Elsevier.

FAO (Food and Agriculture Organization)/IIASA (International Institute for Applied Systems Analysis)/ISRIC (International Soil Reference and Information Centre)/ISSCAS (Institute of Soil Science-Chinese Academy of Sciences)/JRC (Joint Research Centre of the European Commission). 2012. Harmonized World Soil Database (version 1.2). Rome: FAO; Laxenburg, Austria: IIASA. Accessed December 24, 2015. http://webarchive.iiasa.ac.at/Research/LUC/External-World-soil-database/HTML/.

Gardner, B. D., and R. D. Pope. 1978. "How Is Scale and Structure Determined in Agriculture?” American Journal of Agricultural Economics 60: 295-302.

Gellner, D. N. 2007. "Caste, Ethnicity and Inequality in Nepal." Economic and Political Weekly 42 (20): 18231828.

Heckman, J. J. 1979. “Sample Selection Bias as a Specification Error.” Econometrica 47: 153-161.

Heckman, J. J., H. Ichimura, and P. Todd. 1997. "Matching As an Econometric Evaluation Estimator: Evidence from Evaluating a Job Training Programme." Review of Economic Studies 64 (4): 605-654. . 1998. "Matching As an Econometric Evaluation Estimator." Review of Economic Studies 65 (2): 261-294. 
Hirano, K., and G. W. Imbens. 2004. "The Propensity Score with Continuous Treatments.” In Applied Bayesian Modeling and Causal Inference from Incomplete-Data Perspectives, edited by A. Gelman and X.-L. Meng. Chichester, UK: John Wiley \& Sons Ltd.

Imbens, G. W., and D. Rubin. 2009. Causal Inference in Statistics, and in the Social and Biomedical Sciences. New York, NY: Cambridge University Press.

Jacoby, H. G. 1993. "Shadow Wages and Peasant Family Labour Supply: An Econometric Application to the Peruvian Sierra." Review of Economic Studies 60 (4): 903-921.

Jann, B., J. E. Brand, and Y. Xie. 2010. HTE: Stata module to Perform Heterogeneous Treatment Effect Analysis. Accessed December 24, 2015. http://ideas.repec.org/c/boc/bocode/s457129.html.

Key, N., Sadoulet, E. and de Janvry, A. 2000. "Transactions costs and agricultural household supply response.” American Journal of Agricultural Economics 82 (2): 245-259.

Kienzle, J., J. E. Ashburner and B. G. Sims. 2013. Mechanization for Rural Development: A Review of Patterns and Progress from around the World. Rome: Food and Agriculture Organization of the United Nations.

Leuven, E., and B. Sianesi. 2003. PSMATCH2: Stata Module to Perform Full Mahalanobis and Propensity Score Matching, Common Support Graphing, and Covariate Imbalance Testing. Accessed December 24, 2015. http://ideas.repec.org/c/boc/bocode/s432001.html.

Munshi, K. 2004. "Social Learning in a Heterogeneous Population: Technology Diffusion in the Indian Green Revolution." Journal of Development Economics 73:185-213.

Mutuc, M., R. M. Rejesus, and J. M. Yorobe Jr. 2013. "Which Farmers Benefit the Most from Bt Corn Adoption? Estimating Heterogeneity Effects in the Philippines.” Agricultural Economics 44 (2): 231-239.

Nepal, CBS (Central Bureau of Statistics). 1991. Population and Housing Census 1991. Computer disk. Washington, DC.

1996. Nepal Living Standards Survey Report 1996: Main Findings. Vol. 1. Computer disk. Washington, DC.

- 2001. Population and Housing Census 2001. Computer disk. Washington, DC.

2004. Nepal Living Standards Survey II (2003/04): Survey Design and Implementation. Computer disk. Washington, DC.

_.2011a. Nepal Living Standards Survey 2011/11: Statistical Report. Vol. 1. Computer disk. Washington, DC.

-2011b. Population and Housing Census 2011. Computer disk. Washington, DC.

Nunn, N., and D. Puga. 2012. "Ruggedness: The Blessing of Bad Geography in Africa." Review of Economics and Statistics 94: 20-36.

Olmstead, A. L., and P. W. Rhode. 2001. "Reshaping the Landscape: The Impact and Diffusion of the Tractor in American Agriculture, 1910-1960.” Journal of Economic History 61 (03): 663-698.

Poirier, D. J. 1980. "Partial Observability in Bivariate Probit Models." Journal of Econometrics 12 (2): 209-217.

Poirier, D. J., and P. A. Ruud. 1988. "Probit with Dependent Observations.” Review of Economic Studies 55 (4): 593-614.

Ramankutty, N., Evan, A. T., Monfreda, C., and Foley, J. A. 2008. "Farming the Planet: 1. Geographic Distribution of Global Agricultural Lands in the Year 2000." Global Biogeochemical Cycles 22. Accessed December 24, 2015. http://iet.jrc.ec.europa.eu/sites/bf-ca/files/files/documents/ monfreda_biofuelsworkshop2009.pdf

Riley, S. J., S. D. DeGloria, and R. Elliot, 1999. “A Terrain Ruggedness Index That Quantifies Topographic Heterogeneity." Intermountain Journal of Sciences 5 (1-4): 23-27.

Rosenbaum, P. R. 2002. Observational Studies. 2nd edition. New York: Springer. 
Rosenbaum, P. R. and D. B. Rubin. 1983. The Central Role of the Propensity Score in Observational Studies for Causal Effects. Biometrica 70: 41-55.

Roy, K. C., and G. Singh. 2008. "Agricultural Mechanization in Bangladesh.” Agricultural Mechanization in Asia, Africa and Latin America 39 (2): 83-93.

Rubin, D. B. 2001. "Using Propensity Scores to Help Design Observational Studies: Application to the Tobacco Litigation." Health Services and Outcomes Research Methodology 2 (3-4): 169-188.

Smith, J., and P. Todd. 2005. "Does Matching Overcome LaLonde's Critique of Nonexperimental Estimators?" Journal of Econometrics 125 (1-2): 303-353.

Stitzlein, J. N. 1974. "The Economics of Agricultural Mechanization in Southern Brazil." PhD Dissertation, The Ohio State University. Accessed December 24, 2015. pdf.usaid.gov/pdf_docs/PNAAA621.pdf

Takeshima, H. 2015a. "Identifying the Effects of Market Imperfections for a Scale Biased Agricultural Technology: Tractors in Nigeria." Paper presented at the Triennial Conference of the International Association of Agricultural Economists (IAAE), Milan, Italy, August 8-14, 2015.

- 2015b. Market Imperfections for Tractor Service Provision in Nigeria: International Perspectives and Empirical Evidence. IFPRI Discussion Paper 01424. Washington, DC: International Food Policy Research Institute.

. 2015c. Drivers of Growth in Agricultural Returns to Scale: The Hiring In of Tractor Services in the Terai of Nepal. IFPRI Discussion Paper 01476. Washington, DC: International Food Policy Research Institute.

Takeshima, H., A. Adeoti, and S. Salau. 2011. "Measuring the Effect of Transaction Costs for Investment in Irrigation Pumps: Application of Unobserved Stochastic Threshold Model to the Case of Nigeria." African Journal of Agricultural and Resource Economics 6 (2): 118-143.

Takeshima, H., P. Adhikari, and M. Poudel. 2015a. Farm Household Typologies and Mechanization Patterns in Nepal Terai: Descriptive Analysis of Nepal Living Standard Surveys. IFPRI Discussion Paper 01488. Washington, DC: International Food Policy Research Institute.

Takeshima, H., H. Edeh, A. Lawal, and M. Ishiaka. 2015b. "Characteristics of Private-Sector Tractor Service Provisions: Insights from Nigeria.” The Developing Economies 53 (3): 188-217.

Takeshima, H., and L. Nagarajan. 2012. "Minor Millets in Tamil Nadu, India: Local Market Participation, On-Farm Diversity and Farmer Welfare." Environment and Development Economics 17 (5): 603-632.

Takeshima, H., and E. Nkonya. 2014. "Government Fertilizer Subsidy and Commercial Sector Fertilizer Demand: Evidence from the Federal Market Stabilization Program (FMSP) in Nigeria." Food Policy 47: 1-12.

Takeshima, H., and S. Salau. 2010. Agricultural mechanization and the smallholder farmers in Nigeria. NSSP Policy Note 22. Washington, DC: International Food Policy Research Institute.

Takeshima, H., and A. Winter-Nelson. 2012. "Sales Location Among Semi-subsistence Cassava Farmers in Benin: A Heteroskedastic Double Selection Model." Agricultural Economics 43 (6): 655-670.

Thorbecke, E., and T. van der Pluijm. 1993. Rural Indonesia: Socio-economic Development in a Changing Environment, no. 3. New York, NY: New York University Press.

Ugwuishiwu, B. O., and A. P. Onwualu. 2009. "Sustainability and Cost of Agricultural Mechanization in Nigeria as Affected by Macro-Economic Policies." Journal of Agricultural Engineering and Technology 17 (2): 44-56.

U.S. Geological Survey. 1996. Global 30-Arc-Second (GTOPO30) data. Accessed December 24, 2015. https://lta.cr.usgs.gov/GTOPO30.

Xie, Y., J. E. Brand, and B. Jann. 2012. "Estimating Heterogeneous Treatment Effects with Observational Data." Sociological Methodology 42: 314-347.

Zhang, X., J. Yang, and T. Reardon. 2015. Mechanization Outsourcing Clusters and Division of Labor in Chinese Agriculture. IFPRI Discussion Paper 01415. Washington, DC: International Food Policy Research Institute.

Zhao, Z. 2008. "Sensitivity of Propensity Score Methods to the Specifications." Economics Letters 98 (3): 309-319. 




\section{RECENT IFPRI DISCUSSION PAPERS}

\section{For earlier discussion papers, please go to www.ifpri.org/pubs/pubs.htm\#dp. All discussion papers can be downloaded free of charge.}

1507. Determinants of chemical fertilizer use in Nepal: Insights based on price responsiveness and income effects. Hiroyuki Takeshima, Rajendra Prasad Adhikari, Basu Dev Kaphle, Sabnam Shivakoti, and Anjani Kumar, 2016.

1505. Volatile volatility: Conceptual and measurement issues related to price trends and volatility. Eugenio Díaz-Bonilla, 2016.

1504. Changes in Ghanaian farming systems: Stagnation or a quiet transformation? Nazaire Houssou, Michael Johnson, Shashidhara Kolavalli, and Collins Asante-Addo, 2016.

1503. Returns to agricultural public spending in Ghana: Cocoa versus Noncocoa subsector. Samuel Benin, 2016.

1501. Challenges in implementing a small-scale farmers' capacity-building program: The case of the food production, processing, and marketing project in the Democratic Republic of Congo. Catherine Ragasa, Ephraim Nkonya, John Ulimwengu, and Josée Randriamamonjy, 2016.

1500. Leveling the field for biofuels: Comparing the economic and environmental impacts of biofuel and other export crops in Malawi. Franziska Schuenemann, James Thurlow, and Manfred Zeller, 2016.

1499. Farm transition and indigenous growth: The rise to medium- and large-scale farming in Ghana. Nazaire Houssou, Antony Chapoto, and Collins Asante-Addo, 2016.

1498. The impact of agricultural extension services in the context of a heavily subsidized input system: The case of Malawi. Catherine Ragasa, John Mazunda, and Mariam Kadzamira, 2016.

1497. Ghana's macroeconomic crisis: Causes, consequences, and policy responses. Stephen D. Younger, 2016.

1496. Temporary and permanent migrant selection: Theory and evidence of ability-search cost dynamics. Joyce J. Chen, Katrina Kosec, and Valerie Mueller, 2015.

1495. The effect of insurance enrollment on maternal and child healthcare use: The case of Ghana. Gissele Gajate-Garrido and Clement Ahiadeke, 2015.

1494. Stories of change in nutrition: A tool pool. Stuart Gillespie and Mara van den Bold, 2015.

1493. Optimal tariffs with smuggling: A spatial analysis of Nigerian rice policy options. Michael Johnson and Paul Dorosh, 2015.

1492. Smallholders and land tenure in Ghana: Aligning context, empirics, and policy. Isabel Lambrecht and Sarah Asare, 2015.

1491. Returns to agricultural public spending in Africa South of the Sahara. Samuel Benin, 2015.

1490. Lost in translation: The Fractured conversation about trade and food security. Eugenio Díaz-Bonilla, 2015.

1489. Gender roles and food safety in 20 informal livestock and fish value chains. Delia Grace, Kristina Roesel, Erastus Kang'ethe, Bassirou Bonfoh, and Sophie Theis, 2015.

1488. Farm household typologies and mechanization patterns in Nepal Terai: Descriptive analysis of the Nepal Living Standards Survey. Hiroyuki Takeshima, Rajendra Prasad Adhikari, Mahendra Nath Poudel, and Anjani Kumar, 2015.

1487. Public-private partnerships and the reduction of undernutrition in developing countries. John Hoddinott, Stuart Gillespie, and Sivan Yosef, 2015.

1486. How does women's time in reproductive work and agriculture affect maternal and child nutrition?: Evidence from Bangladesh, Cambodia, Ghana, Mozambique, and Nepal. Hitomi Komatsu, Hazel Jean L. Malapit, and Sophie Theis, 2015 .

1485. US maize data reveals adaptation to heat and water stress. Timothy S. Thomas, 2015.

1484. Customary tenure and innovative measures of safeguarding land rights in Africa: The community land initiative (iniciativa de terras comunitárias) in Mozambique. Hosaena Ghebru, Raul Pitoro, and Sileshi Woldeyohannes, 2015. 


\section{INTERNATIONAL FOOD POLICY RESEARCH INSTITUTE}

www.ifpri.org

IFPRI HEADQUARTERS

$2033 \mathrm{~K}$ Street, NW

Washington, DC 20006-1002 USA

Tel.: +1-202-862-5600

Fax: +1-202-467-4439

Email: ifpri@cgiar.org

IFPRI NEW DELHI

NASC, DPS Road, Opp Todapur, Pusa

New Delhi 110-012 India

Tel.: 9111 2584-6565

Fax: 9111 2584-8008 / 2584-6572

Email: ifpri-newdelhi@cgiar.org 